\title{
Intake of saturated and trans unsaturated fatty acids and risk of all cause mortality, cardiovascular disease, and type 2 diabetes: systematic review and meta-analysis of observational studies
}

\author{
Russell J de Souza, , 2,3,4 Andrew Mente, 1, 2,5 Adriana Maroleanu,2 Adrian I Cozma, 3,4 \\ Vanessa Ha, ${ }^{1,3,4}$ Teruko Kishibe, ${ }^{6}$ Elizabeth Uleryk, ${ }^{7}$ Patrick Budylowski, ${ }^{4}$ Holger Schünemann, ${ }^{1,8}$ \\ Joseph Beyene, ${ }^{1,2}$ Sonia S Anand ${ }^{1,2,5,8}$
}

${ }^{1}$ Department of Clinical

Epidemiology and Biostatistics, McMaster University, Hamilton, ON, Canada

${ }^{2}$ Chanchlani Research Centre, McMaster University, Hamilton, ON, Canada

${ }^{3}$ Department of Nutritional Sciences, University of Toronto, Toronto, ON, Canada

${ }^{4}$ Clinical Nutrition and Risk Factor Modification Center, St Michael's Hospital, Toronto, ON, Canada ${ }^{5}$ Population Health Research Institute, Hamilton Health Sciences, Hamilton, ON, Canada

${ }^{6}$ Scotiabank Health Sciences Library, St Michael's Hospital, Toronto, ON, Canada

${ }^{7}$ Hospital Library and Archives, Hospital for Sick Children, Toronto, ON, Canada

${ }^{8}$ Department of Medicine, McMaster University, Hamilton, ON, Canada

Correspondence to: S Anand, McMaster University, 1280 Main St W, MDCL-3204, Hamilton, ON L8N 3Z5, Canada anands@mcmaster.ca

Additional material is published online only. To view please visit the journal online (http://dx.doi. org/10.1136/bmj.h3978)

Cite this as: $B M J$ 2015;351:h3978 doi: 10.1136/bmj.h3978

Accepted: 15 July 2015

\section{ABSTRACT}

OBJECTIVE

To systematically review associations between intake of saturated fat and trans unsaturated fat and all cause mortality, cardiovascular disease (CVD) and associated mortality, coronary heart disease (CHD) and associated mortality, ischemic stroke, and type 2 diabetes.

DESIGN

Systematic review and meta-analysis.

\section{DATA SOURCES}

Medline, Embase, Cochrane Central Registry of Controlled Trials, Evidence-Based Medicine Reviews, and CINAHL from inception to 1 May 2015, supplemented by bibliographies of retrieved articles and previous reviews.

\section{ELIGIBILITY CRITERIA FOR SELECTING STUDIES} Observational studies reporting associations of saturated fat and/or trans unsaturated fat (total, industrially manufactured, or from ruminant animals) with all cause mortality, CHD/CVD mortality, total CHD, ischemic stroke, or type 2 diabetes.

\section{DATA EXTRACTION AND SYNTHESIS}

Two reviewers independently extracted data and assessed study risks of bias. Multivariable relative risks were pooled. Heterogeneity was assessed and quantified. Potential publication bias was assessed and subgroup analyses were undertaken. The GRADE approach was used to evaluate quality of evidence and certainty of conclusions.

\section{WHAT IS ALREADY KNOWN ON THIS TOPIC}

Contrary to prevailing dietary advice, authors of a recent systematic review and meta-analyses claim that there is no excess cardiovascular risk associated with intake of saturated fat, and the US has recently taken policy action to remove partially hydrogenated vegetable oils from its food supply

Population health guidelines require a careful review and assessment of the evidence of harms of these nutrients, with a focus on replacement nutrients

\section{WHAT THIS STUDY ADDS}

This study reviewed prospective observational studies and assessed the certainty of the associations with GRADE methods

There was no association between saturated fats and health outcomes in studies where saturated fat generally replaced refined carbohydrates, but there was a positive association between total trans fatty acids and health outcomes Dietary guidelines for saturated and trans fatty acids must carefully consider the effect of replacement nutrients

\section{RESULTS}

For saturated fat, three to 12 prospective cohort studies for each association were pooled (five to 17 comparisons with 90501-339090 participants). Saturated fat intake was not associated with all cause mortality (relative risk $0.99,95 \%$ confidence interval 0.91 to 1.09$)$, CVD mortality (0.97, 0.84 to 1.12$)$, total CHD (1.06, 0.95 to 1.17), ischemic stroke $(1.02,0.90$ to $1.15)$, or type 2 diabetes $(0.95,0.88$ to 1.03$)$. There was no convincing lack of association between saturated fat and CHD mortality $(1.15,0.97$ to $1.36 ; \mathrm{P}=0.10)$. For trans fats, one to six prospective cohort studies for each association were pooled (two to seven comparisons with $12942-230135$ participants). Total trans fat intake was associated with all cause mortality (1.34, 1.16 to 1.56), CHD mortality (1.28, 1.09 to 1.50), and total CHD (1.21, 1.10 to 1.33$)$ but not ischemic stroke (1.07, 0.88 to 1.28$)$ or type 2 diabetes $(1.10,0.95$ to 1.27). Industrial, but not ruminant, trans fats were associated with CHD mortality (1.18 (1.04 to 1.33) v1.01 (0.71 to 1.43)) and CHD (1.42 (1.05 to 1.92) v 0.93 (0.73 to 1.18)). Ruminant trans-palmitoleic acid was inversely associated with type 2 diabetes $(0.58,0.46$ to 0.74$)$. The certainty of associations between saturated fat and all outcomes was "very low." The certainty of associations of trans fat with CHD outcomes was "moderate" and "very low" to "low" for other associations.

\section{CONCLUSIONS}

Saturated fats are not associated with all cause mortality, CVD, CHD, ischemic stroke, or type 2 diabetes, but the evidence is heterogeneous with methodological limitations. Trans fats are associated with all cause mortality, total CHD, and CHD mortality, probably because of higher levels of intake of industrial trans fats than ruminant trans fats. Dietary guidelines must carefully consider the health effects of recommendations for alternative macronutrients to replace trans fats and saturated fats.

\section{Introduction}

Recent high profile opinion pieces, informed by systematic reviews of randomized trials ${ }^{12}$ and prospective cohort studies, ${ }^{13}$ have called for a re-evaluation of dietary guidelines for intake and a re-appraisal of the effects of saturated fat on health; during this time public health efforts to remove trans fats from the food supply in several countries have intensified.

Saturated fats contribute about $10 \%$ of energy to the North American diet. ${ }^{45}$ The main sources of saturated 
fatty acids in the food supply are animal products, such as butter, cows' milk, meat, salmon, and egg yolks, and some plant products such as chocolate and cocoa butter, coconut, and palm kernel oils. Previous meta-analyses of prospective cohort studies reported pooled relative risk estimates comparing extremes of intake of saturated fat of 1.07 (95\% confidence interval 0.96 to 1.19 ; $\mathrm{P}=0.22$ ) for coronary heart disease (CHD), 0.81 (0.62 to 1.05; $\mathrm{P}=0.11$ ) for stroke, and 1.00 (0.89 to $1.11 ; \mathrm{P}=0.95)$ for cardiovascular disease (CVD). ${ }^{6}$ Intervention trials have shown modest cardiovascular benefits of reducing intake of saturated fat while increasing intake of polyunsaturated fat, ${ }^{7}$ but most trials lasted only up to two years and examined surrogate outcomes. A meta-analysis of randomized trials suggested a $17 \%$ reduction in risk of CVD in studies that reduced saturated fat intake from about $17 \%$ to about $9 \%$ of energy ( $0.83,0.72$ to 0.96$){ }^{8}$

Trans fats contribute about $1-2 \%$ of energy in the North American diet ${ }^{9-11}$ and are produced industrially through partial hydrogenation of liquid plant oils in the presence of a metal catalyst, vacuum, and high heat or can occur naturally in meat and dairy products, where ruminant animals biohydrogenate unsaturated fatty acids via bacterial enzymes. The major industrially produced trans fatty acids in the food supply are elaidic acid isomers, and the major ruminant derived trans fatty acid is vaccenic acid; both share the characteristic of having at least one double bond in the "trans-" rather than "cis-" configuration. A prior meta-analysis reported pooled relative risk estimates of CHD of 1.22 (95\% confidence interval 1.08 to 1.38 ; $\mathrm{P}=0.002$ ) for extremes of total intake of trans fats; 1.30 (0.80 to 2.14; $\mathrm{P}=0.29$ ) for intake of industrially produced trans fats; and 0.93 ( 0.74 to $1.18 ; \mathrm{P}=0.56$ ) for intake of ruminant derived trans fats, ${ }^{12}$ suggesting that industrially produced trans fats might increase the risk of CHD, though this could also reflect the low levels of ruminant derived trans fats compared with the higher doses of industrially produced trans fats typically consumed in studies and available in the food supply. ${ }^{13}$

Dietary guidelines recommend that saturated fats should be limited to $<10 \%$ (5-6\% for those who would benefit from lowering of LDL cholesterol), and trans fats to $<1 \%$ of energy or as low as possible, ${ }^{14-19}$ primarily to reduce risk of ischemic heart disease and stroke. To clarify controversies surrounding guidelines for saturated and trans fats for adults, we have extended and updated previous work to synthesize prospective associations between these fats and all cause mortality and type 2 diabetes (which have not been previously synthesized), separate estimates for risks of cardiovascular morbidity and mortality, and assess the confidence in the observational evidence using the Grading of Recommendations Assessment, Development and Evaluation (GRADE) approach. ${ }^{20-22}$

\section{Methods}

This review was conducted in accordance with the WHO's guideline development process, ${ }^{23}$ based on the Cochrane Collaboration approach ${ }^{24}$ and reported according to the MOOSE checklist. ${ }^{25}$

\section{Data sources}

We conducted independent searches for relevant observational studies assessing the association between saturated and/or trans fats and health outcomes up to 1 May 2015 (appendix 1 gives full details). This included searching Medline (from 1946), Embase (from 1974), Cochrane Central Registry of Controlled Trials (from 1996), Evidence Based Medicine Reviews (from 1996), and CINAHL (from 1983). Reference lists of retrieved articles and previous systematic and narrative reviews ${ }^{1}{ }^{1226-29}$ were hand searched. There were no language restrictions.

\section{Study selection}

Eligible studies included any observational study conducted in humans (such as prospective cohort, case-control, nested case-control, or case-cohort design) that reported a measure of association (such as hazard ratios or incident rate ratios for prospective studies; or odds ratios for retrospective studies) between intakes of saturated or trans fat, measured by self report or a biomarker, and all cause mortality, coronary heart disease, stroke, or type 2 diabetes, measured by self report, and/or confirmed by medical records or registry linkage. One reviewer assessed titles and abstracts of all studies identified through electronic searches. Potentially eligible studies were reviewed independently by a second reviewer, with discrepancies resolved by discussion; and when necessary, a senior author was consulted to reach consensus.

\section{Data extraction}

Pairs of authors independently extracted details of the study design, country of conduct, exposure and outcome assessment, participant characteristics, and statistical analyses, including adjustment for confounders, from included studies using pretested instruments (see appendix 1), with discrepancies resolved by discussion. Authors were contacted for additional data, when necessary. We used Plot Digitizer (http://plotdigitizer. sourceforge.net/) to extract numerical estimates from graphs.

\section{Assessment of trans fats exposure methods}

To assess the accuracy of measures of trans fats in studies that did not directly measure concentrations in blood or adipose tissues, we assessed the potential for misclassification. The lowest risk of misclassification was for those studies that used a food frequency questionnaire validated against multiple day prospective diet records or 24 hour recalls; directly measured adipose tissue trans fatty acids in a subset of the population; and analyzed dietary intake with an updated database of foods. A study was rated as at low risk of misclassification if it accomplished all three; moderate risk of misclassification) if it accomplished two of three; high risk of misclassification if it accomplished one of three; or at very high risk of misclassification if it did not accomplish any. For assessment of ruminant trans fats, the most common approach was to use the known nutrient composition from food tables for dairy and 
meat products to estimate ruminant trans fats and possibly supplemented by direct measurement with gas chromatography (see eTable 1 in appendix 2).

\section{Study risk of bias}

We used the Newcastle-Ottawa scale ${ }^{30}$ to assess the risk of bias of the included studies on the basis of selection of study groups, comparability of groups, and ascertainment of exposure(s) or outcome(s).

\section{Grading of recommendations assessment,} development, and evaluation (GRADE)

The GRADE approach was used to assess the confidence in the effect estimates derived from the body of evidence (quality of evidence) by outcome and produce evidence profiles. ${ }^{20-22}$ We limited the presentations of results in the main text to the synthesis of prospective cohort studies as these are considered the highest level of evidence for observational studies and thus were used for the GRADE assessments of confidence. Appendix 3 provides full details of designs that did not directly inform GRADE (that is, retrospective case-control studies and other studies not amenable to quantitative synthesis). All investigators discussed and reviewed evidence summaries and GRADE assessments, which were reviewed with the WHO Nutrition Guidance Expert Advisory Group (NUGAG) subgroup on diet and health as part of WHO's guideline development process. Confidence in the estimate of each association was categorized into four levels, from very low to high.

\section{Data synthesis and analysis}

Statistical synthesis of effect estimates

The principal association measures were the risk ratios between extreme levels of intake (highest $v$ lowest) for prospective studies and the odds ratio between extreme levels of exposure (highest $v$ lowest) for retrospective studies. For each study, we calculated most adjusted (that is, the multivariable association measure with the highest number of covariates) and least adjusted (that is, the multivariable association measure with the fewest number of covariates) estimates and corresponding 95\% confidence intervals for each outcome. We extracted both estimates to assess whether relevant confounders (such as smoking, age) and intermediate variables (such as LDL cholesterol, blood pressure) were captured in the statistical models. Analyses that adjust for potential confounders and intermediate variables will generally represent conservative estimates of the strength of the associations, and analyses that do not adjust for these will generally reflect the effect not only of exposure to fat but of other determinants of the health outcomes. We present both models to assess the impact of these variables on the reported association. When at least two studies provided data, we performed a DerSimonian and Laird random effects meta-analysis, which yields conservative confidence intervals around relative risks in the presence of heterogeneity. ${ }^{31}$ When three or fewer studies were combined, we also considered fixed effect estimates.

\section{Heterogeneity}

Heterogeneity was determined with Cochran's Q test (significant at $\mathrm{P}<0.10$ ), quantified with the $\mathrm{I}^{2}$ statistic (range from 0\%-100\%), ${ }^{32}$ and used to assess inconsistency as part of the GRADE assessment of evidence quality. If $\geq 10$ studies were available ${ }^{33} 34$ and heterogeneity was substantial $\left(\mathrm{I}^{2}>60 \%\right.$ or $\left.\mathrm{P}_{\mathrm{Q}}<0.10\right),{ }^{32}$ we used meta-regression to explore heterogeneity by baseline year of study, continent of conduct, length of follow-up, median age of participants, proportion of smokers in the sample, amount of saturated fat in reference category, mean saturated or trans fat intake of the population, sex, $\alpha$-linoleic acid, total polyunsaturated fat, adjustment for total energy, method and frequency of exposure assessment, risk of bias score, and adjustment for lipids or blood pressure (that is, causal intermediates).

\section{Sensitivity}

We carried out four a priori sensitivity analyses. We removed each single study from the meta-analyses and recalculated the summary association (the "leave one out" approach); ${ }^{35}$ removed studies with scores $<7$ on the Newcastle-Ottawa scale and recalculated the pooled association; included unpublished data on trans fats and CHD mortality (P Knekt, personal communication); and removed risk estimates imputed because of incomplete reporting. A study whose removal either pushed the significance level of the overall association from $<0.05$ to $\geq 0.05$ (or vice versa), or altered the nominal effect size by $10 \%$ or more, was considered an influential outlier. At the request of the WHO's Nutrition Guidelines Advisory Committee (10 July 2015), we performed two post hoc sensitivity analyses, limited to comparisons in which the estimated dietary intake of trans fatty acids was $<1 \%$ of energy in the referent group and $\geq 1 \%$ of energy in the highest exposure category.

\section{Publication bias}

If $\geq 10$ studies were available, ${ }^{36}$ we explored the possibility of publication bias by inspecting funnel plots and conducting Egger's and Begg's tests (each significant at $\mathrm{P}<0.10$ ). If publication bias was suspected, results are shown without imputation and with "missing" studies imputed with Duval and Tweedie's trim and fill method. ${ }^{37}$

\section{Software}

Primary summary analyses were carried out separately for each outcome with Review Manager, version 5.2 (Nordic Cochrane Center, Cochrane Collaboration, Copenhagen). Meta-regression and sensitivity analyses were undertaken with Stata, version 12.1 (StataCorp, College Station, TX).

\section{Patient involvement}

No patients were involved in setting the research question or the outcome measures, nor were they involved in the design and implementation of the study. There are no plans to involve patients in dissemination. 


\section{Results}

\section{Saturated fats and health outcomes}

Literature flow

We identified 20413 potentially eligible articles. After full text review, 41 primary reports of associations between saturated fats and health outcomes in prospective cohort studies (published between 1981 and 2014) provided 67 data points that contributed to the quantitative synthesis. Cohorts were enrolled from the United States (17 studies, 25 data points), the United Kingdom (four studies, six data points), Japan (four studies, nine data points), Sweden (four studies, seven data points), Israel (one study, four data points), Finland (three studies, four data points), Denmark (one study, four data points), Canada (one study, two data points), China (one study, one data point), Greece (one study, one data point), and Australia (one study, one data point) (fig 1; appendix 2 provides full study characteristics in eTables 2-4 and scores on the Newcastle-Ottawa scale in eTables 5-6). The Seven Countries' study, with cohorts enrolled from the US, Finland, the Netherlands, Italy, the former Yugoslavia (Serbia and Croatia), Greece, and Japan, is discussed separately as its design was not appropriate for pooling. Meta-regression analyses, summaries of results for case-control studies, nested case-control studies, dose-response/substitution relations, and studies that did not directly bear on the GRADE evidence table are presented in appendix 3 and eTables 7-10 in appendix 2.

\section{All cause mortality}

Six prospective investigations examined the association between intake of saturated fats and all cause mortality. The Seven Countries Study ${ }^{38}$ (12763 men), which could not be included in the quantitative synthesis because of an incompatible association measure, reported large differences in intake across countries, from 3.9\% (Tanushimaru, Japan) to 22.7\% (East Finland). Over 25

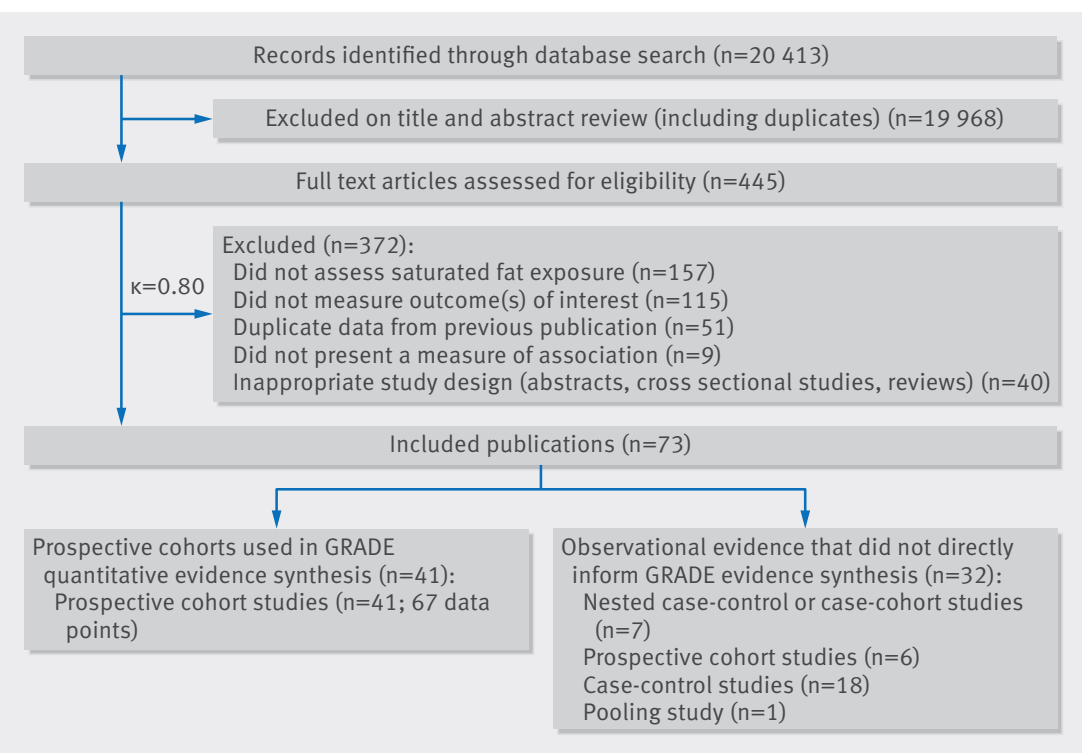

Fig 1 PRISMA summary of evidence search and selection for saturated fat and health outcomes (up to 1 May 2015) years of follow-up, 5973 (47\%) deaths were reported. In a multivariable regression model, a 5\% increase in energy from saturated fats was associated with a $4.7 \%$ increase in age adjusted all cause mortality rate. For saturated fats and all cause mortality, ${ }^{39-43}$ the summary most adjusted multivariable risk ratio was $0.99(95 \%$ confidence interval 0.91 to $1.09 ; \mathrm{P}=0.91 ; \mathrm{I}^{2}=33 \%$; $\mathrm{P}_{\text {het }}=0.17$ ) (fig 2; appendix 4 eFigure 1). Subgroup analyses or publication bias tests were not performed $(<10$ studies).

\section{Fatal and total CHD and CVD}

For saturated fats and CHD mortality, ${ }^{404144-52}$ the summary most adjusted multivariable risk ratio was 1.15 (95\% confidence interval 0.97 to $1.36 ; \mathrm{P}=0.10 ; \mathrm{I}^{2}=70 \%$; $\mathrm{P}_{\text {het }}<0.001$ ) (fig 2; appendix 4 eFigure 3). The summary least adjusted risk ratio was 1.20 (1.02 to 1.41 ; $\mathrm{P}=0.02$; $\mathrm{I}^{2}=74 \%$; $\mathrm{P}_{\text {het }}<0.001$ ) (appendix 4 eFigure 4). As risk estimates of four comparisons could not be directly extracted, ${ }^{47850}$ we used the estimates reported in a previous meta-analysis. ${ }^{3}$ Removal of these four comparisons resulted in a summary risk ratio of 1.26 (0.98 to 1.62; $\left.\mathrm{P}=0.07 ; \mathrm{I}^{2}=74 \% ; \mathrm{P}_{\text {het }}<0.001\right)$. Removal of the age group $>60$ in the study by Goldbourt and colleagues ${ }^{47}$ or the study by Pietinen and colleagues ${ }^{49}$ shifted the overall estimate to 1.20 (1.01 to $1.42 ; \mathrm{P}=0.04 ; \mathrm{I}^{2}=68 \%$; $\mathrm{P}_{\text {het }}<0.001$ ), suggesting these two studies were influential outliers. For CVD mortality, the summary most adjusted multivariable risk ratio (five comparisons) $)^{39} 4353$ was 0.97 ( 0.84 to $1.12 ; \mathrm{P}=0.69 ; \mathrm{I}^{2}=19 \%$; $\mathrm{P}_{\text {het }}=0.29$ ) (fig 2; appendix 4 eFigure 3).

For saturated fats and total CHD, ${ }^{449-62}$ the summary most adjusted multivariable risk ratio was 1.06 (95\% confidence interval 0.95 to $1.17 ; \mathrm{P}=0.29 ; \mathrm{I}^{2}=47 \%$; $\mathrm{P}_{\text {het }}=0.02$ ) (fig 2; appendix 4 eFigure 5). As risk estimates from three comparisons ${ }^{548}$ could not be extracted, we used estimates reported in a previous meta-analysis. ${ }^{3}$ Removal of these three comparisons resulted in a summary risk ratio of 1.08 (0.97 to 1.20; $\left.\mathrm{P}=0.18 ; \mathrm{I}^{2}=51 \% ; \mathrm{P}_{\text {het }}=0.01\right)$. The summary least adjusted relative risk was 1.12 (1.00 to $1.26 ; \mathrm{P}=0.05 ; \mathrm{I}^{2}=63 \%$; $\mathrm{P}_{\text {het }}<0.001$ ) (appendix 4 eFigure 6). No study was an influential outlier.

For saturated fats and ischemic stroke, $475357586163-70$ the summary most adjusted multivariable risk ratio was 1.02 (95\% confidence interval 0.90 to 1.15 ; $\mathrm{P}=0.79$; $\mathrm{I}^{2}=59 \% ; \mathrm{P}_{\text {het }}=0.002$ ) (fig 2; appendix 4 eFigure 7 ). As risk estimates for four comparisons ${ }^{475458}$ could not be extracted, we used estimates reported in a previous meta-analysis. ${ }^{3}$ Removal of these four comparisons resulted in a summary risk ratio of 1.03 (0.89 to 1.19; $\left.\mathrm{P}=0.68 ; \mathrm{I}^{2}=66 \% ; \mathrm{P}_{\text {het }}<0.001\right)$. The summary least adjusted risk ratio was 1.03 ( 0.91 to $1.16 ; \mathrm{P}=0.65 ; \mathrm{I}^{2}=66 \%$; $\mathrm{P}_{\text {het }}<0.001$ ) (appendix 4 eFigure 8). No study was an influential outlier.

\section{Type 2 diabetes}

For saturated fats and type 2 diabetes, ${ }^{71-7778}$ the summary most adjusted multivariable risk ratio was 0.95 (95\% confidence interval 0.88 to $1.03 ; \mathrm{P}=0.20 ; \mathrm{I}^{2}=0 \%$; $\mathrm{P}_{\text {het }}=0.61$ ) (fig 2; appendix 4 eFigure 9). The summary 


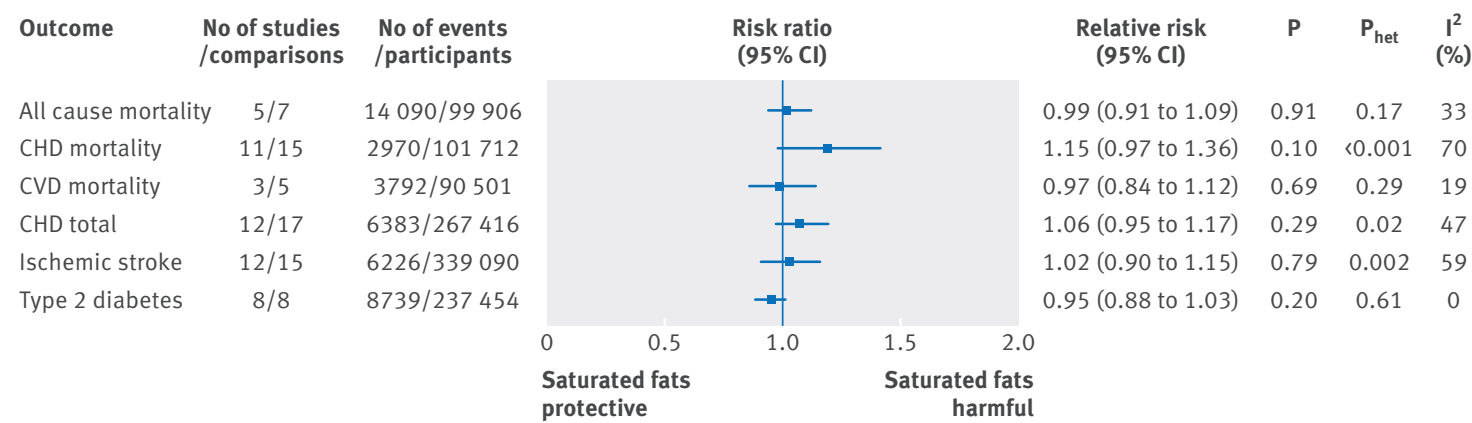

Fig 2 | Summary most adjusted relative risks for saturated fat intake and all cause mortality, CHD mortality, CVD mortality, total CHD, ischemic stroke, and type 2 diabetes. All effect estimates are from random effects analyses. $P$ value is for $Z$ test of no overall association between exposure and outcome; $P_{\text {het }}$ is for test of no differences in association measure among studies; $I^{2}$ is proportion of total variation in study estimates from heterogeneity rather than sampling error

least adjusted risk ratio was 1.23 (0.98 to 1.52; $\mathrm{P}=0.07$; $\mathrm{I}^{2}=91 \% ; \mathrm{P}_{\text {het }}<0.001$ ) (appendix 4 eFigure 10). No study was an influential outlier.

\section{Trans fats and health outcomes Literature flow}

We identified 18835 potentially eligible articles (fig 3). After full text review, 20 primary reports of associations between total trans fats and the health outcomes in prospective cohort studies (published between 1996 and 2015) provided 28 data points that contributed to the quantitative synthesis. Cohorts were enrolled from the US (14 studies, 19 data points), Finland (four studies, six data points), China (one study, one data point), and the Netherlands (one study, two data points). One systematic review contributed one data point

\begin{tabular}{|c|c|c|}
\hline \multicolumn{3}{|c|}{ Records identified through database search $(n=18835)$} \\
\hline & \multicolumn{2}{|c|}{ Excluded on title and abstract review (including duplicates) $(n=18633)$} \\
\hline \multicolumn{3}{|c|}{ Full text articles assessed for eligibility $(n=202)$} \\
\hline $\mathrm{K}=0.80$ & \multicolumn{2}{|c|}{$\begin{array}{l}\text { Excluded ( } n=153) \text { : } \\
\text { Did not assess trans fat exposure }(n=56) \\
\text { Cross sectional studies }(n=22) \\
\text { Did not allow isolation of trans fat effect }(n=19) \\
\text { Did not present a measure of association }(n=13) \\
\text { Did not measure outcome }(s) \text { of interest }(n=26) \\
\text { Could not obtain original article }(n=3) \\
\text { Other (editorials, commentaries, reviews, case series, duplicate publications, } \\
\text { abstracts only }(n=14)\end{array}$} \\
\hline & \multicolumn{2}{|c|}{ Previously unpublished data added during manual search $(n=1)$} \\
\hline \multicolumn{3}{|c|}{ Included publications $(n=50)$} \\
\hline & $\sqrt{1}$ & 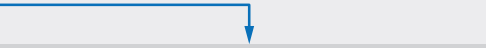 \\
\hline $\begin{array}{l}\text { Prospective cohor } \\
\text { evidence synthe } \\
\text { Total trans fats: } \\
\text { ( } \mathrm{n}=20 ; 28 \text { dat } \\
\text { Industrial trans } \\
\text { studies }(\mathrm{n}=4 ; \\
\text { Ruminant trans } \\
\text { studies }(\mathrm{n}=9 ;\end{array}$ & $\begin{array}{l}\text { ts used in GRADE quantitative } \\
\text { sis ( } \mathrm{n}=33 \text { ): } \\
\text { Prospective cohort studies } \\
\text { a points) } \\
\text { fats: Prospective cohort } \\
4 \text { data points) } \\
\text { fats: Prospective cohort } \\
13 \text { data points) }\end{array}$ & $\begin{array}{l}\text { Observational evidence that did not directly } \\
\text { inform GRADE evidence synthesis }(n=17) \text { : } \\
\text { Nested case-control or case-cohort studies } \\
(n=6) \\
\text { Case-control studies }(n=11)\end{array}$ \\
\hline
\end{tabular}

Fig 3 | PRISMA summary of evidence search and selection for trans unsaturated fat and health outcomes (up to 1 May 2015) from a previously unpublished prospective cohort study, ${ }^{12}$ and one author provided updated unpublished data from the Finnish Mobile Health clinics (P Knekt, personal communication). Four primary reports of associations between industrial trans fats and the health outcomes (published between 1993 and 2013) provided four data points that contributed to the quantitative synthesis. Cohorts were enrolled from the US (one study, one data point), Finland (one study, one data point), the Netherlands (one study, one data point), and Norway (one study, one data point). Nine primary reports of associations between ruminant trans fats and the health outcomes (published between 1993 and 2015) provided 13 data points that contributed to the quantitative synthesis. Cohorts came from the US (five studies; five data points), Norway (one study, four data points), Finland (one study, one data point), Denmark (one study, two data points), and the Netherlands (one study, one data point). Appendix 2 shows full study characteristics: in eTable 11 for prospective cohort studies, eTable 12 for retrospective case-control studies, eTable 13 for nested case-control or case-cohort studies, and eTables 5 and 6 for scores on the Newcastle-Ottawa scale. Summaries of results for case-control studies, nested case-control studies, dose-response/substitution relations, and studies that did not inform the GRADE evidence table are presented in appendix 3. We use the term "total trans fats" to refer to the estimate of exposure to all trans fats, whether industrially produced or ruminant derived, and present specific associations of industrially produced and ruminant derived trans fats with health outcomes separately, when available. The specificity of trans fat measurement provided by each study is presented in appendix 2 eTables 1, 11, 12, and 13.

\section{All cause mortality}

The pooled random effects most adjusted multivariable risk ratio of high versus low total intake of trans unsaturated fatty acid estimated from two published reports ${ }^{42} 79$ (two comparisons) including 2141 deaths in 20346 individuals was 1.42 (95\% confidence interval 1.04 to 1.94 ; $\mathrm{P}=0.03$ ), with some evidence of heterogeneity between studies $\left(\mathrm{I}^{2}=70 \% ; \mathrm{P}_{\text {het }}=0.07\right)$ appendix 4 eFigure 11$)$. 
Because of the small number of studies, and the lower power to estimate $\tau$ for random effects analysis, we also performed a fixed effect meta-analysis, which results in a pooled association of 1.34 (1.16 to 1.56; $\mathrm{P}<0.001$; $\mathrm{I}^{2}=70 \% ; \mathrm{P}_{\text {het }}=0.07$ (fig 4, appendix 4 eFigure 12). The least adjusted estimate was 1.80 (1.57 to 2.07; $\left.\mathrm{P}<0.001 ; \mathrm{I}^{2}=0 \% ; \mathrm{P}_{\text {het }}=0.71\right)$, presented in appendix 4 eFigures 13 and 14.

\section{Fatal and total CHD and CVD}

For total trans fats and CHD mortality, 4449515280 the summary most adjusted multivariable risk ratio was 1.28 (95\% confidence interval 1.09 to $1.50 ; \mathrm{P}=0.003$; $\mathrm{I}^{2}=0 \%$; $\mathrm{P}_{\text {het }}=0.66$; fig 4; appendix 4 eFigure 15 ; the least adjusted figure is shown in appendix 4 eFigure 16). Removal of the study by Pietinen and colleagues ${ }^{49}$ resulted in a relative risk of 1.20 ( 0.96 to 1.48 ; $\mathrm{P}=0.10$; $\left.\mathrm{I}^{2}=0 \% ; \mathrm{P}_{\text {het }}=0.65\right)$. Addition of three unpublished comparisons from two cohorts, including updated data from one investigator ( $\mathrm{P}$ Knekt, personal communication) ${ }^{12}$ weakened the estimate $(1.22,1.07$ to 1.38 ; $\mathrm{P}=0.002 ; \mathrm{I}^{2}=0 \% ; \mathrm{P}_{\text {het }}=0.46$ ) (appendix 4 eFigure 17; least adjusted eFigure 18).

For total trans fats and total CHD, 444951555980 the summary most adjusted multivariable risk ratio was 1.21 (1.10 to 1.33; $\mathrm{P}<0.001 ; \mathrm{I}^{2}=0 \%$; $\mathrm{P}_{\text {het }}=0.43$; fig 4; appendix 2 eFigure 19; least adjusted in eFigure 20). We included data from one randomized trial ${ }^{55}$ as the report allowed a comparison of usual (about 2.5\%) versus low $(<1.1 \%)$ intake of trans fat at one year. Its removal did not alter the estimate of association (1.22, 1.08 to 1.38 ; $\mathrm{P}=0.002$; $\left.\mathrm{I}^{2}=15 \% ; \mathrm{P}_{\text {het }}=0.32\right)$.
For total trans fats and ischemic stroke 656981 the summary most adjusted multivariable risk ratio was 1.07 (95\% confidence interval 0.88 to $1.28 ; \mathrm{P}=0.50$ ) (fig 4; appendix 4 eFigure 21 and least adjusted in eFigure 22). There was, however, considerable heterogeneity between studies $\left(I^{2}=67 \%\right.$; $\left.P_{\text {het }}=0.03\right)$.

\section{Type 2 diabetes}

For total trans fats and type 2 diabetes, ${ }^{72-76} 82$ the summary most adjusted multivariable risk ratio was 1.10 (95\% confidence interval 0.95 to $1.27 ; \mathrm{P}=0.21 ; \mathrm{I}^{2}=66 \%$; $\mathrm{P}_{\text {het }}=0.01$ ) (fig 4; appendix 4 eFigure 23). Removal of one moderate quality study ${ }^{72}$ did not alter the estimate (1.14, 0.98 to $1.32 ; \mathrm{P}=0.10 ; \mathrm{I}^{2}=63 \%$; $\mathrm{P}_{\text {het }}=0.03$ ). Pooling of minimally adjusted associations yielded a $28 \%$ increased risk of type 2 diabetes (1.28, 1.05 to $1.55 ; \mathrm{P}=0.01 ; \mathrm{I}^{2}=87 \%$; $\mathrm{P}_{\text {het }}<0.001$; appendix 4 eFigure 24).

\section{Industrially produced trans fats}

The Norwegian Countries prospective cohort study ${ }^{83}$ (71464 participants; 25.8 year follow-up) found no association between industrially produced trans fats from partially hydrogenated vegetable (PHVO) or fish oils (PHFO) and all cause mortality (11980 deaths). The multivariable adjusted risk ratio was 0.96 (95\% confidence interval 0.88 to 1.05 ; $\mathrm{P}=0.11$ for trend) for high ( $\geq 1.65 \%$ of energy) versus low ( $<0.15 \%$ of energy) PHVO, and 1.00 ( 0.92 to 1.10; $\mathrm{P}=0.11$ for trend) for high ( $\geq 2.35 \%$ of energy) versus low ( $<0.85 \%$ of energy) PHFO (fig 4 shows the pooled risk ratio of $\mathrm{PHVO}$ and PHFO; $\mathrm{I}^{2}=0 \%$ $\mathrm{P}_{\text {het }}=0.52$ ). Two studies showed that industrially produced trans fats are associated with CHD mortality

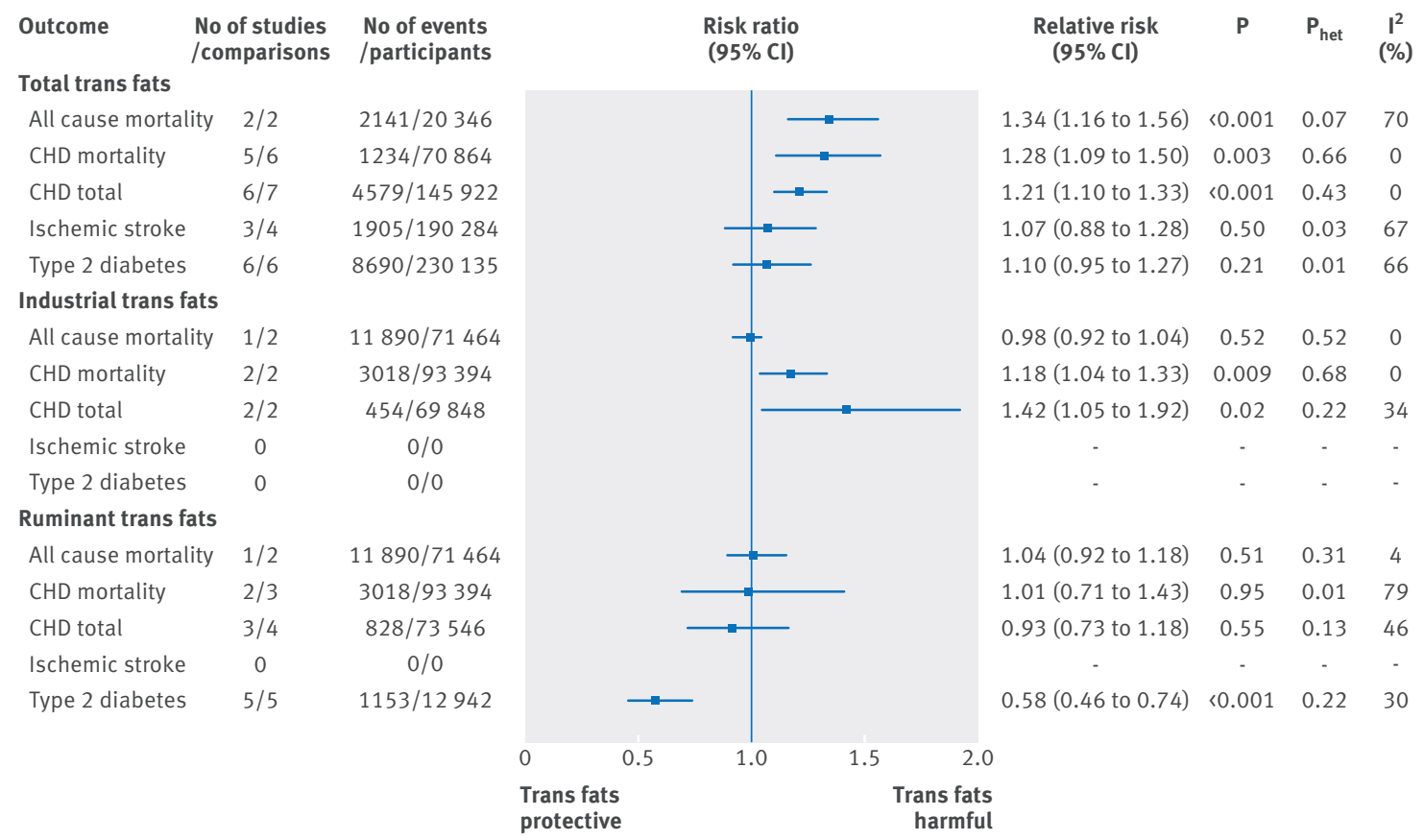

Fig 4 | Summary most adjusted relative risks of total trans fat, industrial trans fat, and ruminant trans fat and all cause mortality, CHD mortality, total CHD, ischemic stroke, and type 2 diabetes. For total trans fats effect estimate for is fixed effect analysis; all others random effects analyses. $P$ value is for $Z$ test of no overall association between exposure and outcome; $P_{\text {het }}$ is for test of no differences in association measure among studies; $I^{2}$ is proportion of total variation in study estimates from heterogeneity rather than sampling error 
(1.18, 1.04 to $1.33 ; \mathrm{P}=0.009 ; \mathrm{I}^{2}=0 \% ; \mathrm{P}_{\text {het }}=0.68$; fig 4; appendix 4 eFigures 25-28). 4983 Two other studies showed that industrially produced trans fats are associated with total CHD (1.42, 1.05 to $1.92 ; \mathrm{P}=0.02 ; \mathrm{I}^{2}=34 \%$; $\left.\mathrm{P}_{\text {het }}=0.22\right)^{8084}$ (fig 4; appendix 4 eFigures 29-32). We did not find any prospective cohort studies of total intake of industrially produced trans fats and risk of ischemic stroke or type 2 diabetes.

\section{Ruminant derived trans fats}

In the Norwegian Countries prospective cohort study ${ }^{83}$ the multivariable adjusted risk ratio for all cause mortality was 1.04 (95\% confidence interval 0.92 to 1.18 ; $\left.\mathrm{P}=0.51 ; \mathrm{I}^{2}=4 \% ; \mathrm{P}_{\text {het }}=0.31\right)$ for the highest versus lowest categories of ruminant derived trans fats (fig 4; appendix 4 eFigure 33-34). Two studies found no association between ruminant derived trans fats and CHD mortality $^{4983}$ (1.01, 0.71 to 1.43; $\mathrm{P}=0.95 ; \mathrm{I}^{2}=79 \%$; $\mathrm{P}_{\text {het }}=0.01$ ) (fig 4; appendix 4 eFigure 35-36). Three studies found no association between ruminant derived trans fats and total $\mathrm{CHD}^{80} 8485$ (0.93, 0.73 to 1.18; $\mathrm{P}=0.55 ; \mathrm{I}^{2}=46 \%$; $\mathrm{P}_{\text {het }}=0.13$ ) (fig 4; appendix 4 eFigure 37-40). Removal of the study by Jakobsen and colleagues ${ }^{85}$ (in men) resulted in a pooled risk ratio of 0.83 (0.59 to $1.15 ; \mathrm{P}=0.26 ; \mathrm{I}^{2}=28 \%$; $\mathrm{P}_{\text {het }}=0.25$ ), which met our definition of an "influential outlier." Five studies found an inverse association between 16:1 n-7 trans-palmitoleic acid, principally derived from dairy, and type 2 diabetes $^{82}$ 86-89 $^{80.58,0.46}$ to $0.74 ; \mathrm{P}<0.001 ; \mathrm{I}^{2}=30 \%$; $\mathrm{P}_{\text {het }}=0.22$; fig 4; appendix 4 eFigures 41-42). We did not find any prospective cohort studies of ruminant derived trans fats and risk of ischemic stroke.

\section{GRADE confidence in estimates of association}

For the GRADE confidence in estimates of association, we considered only prospective cohort studies because these are generally considered the highest level of observational study design..$^{90}$ Overall, the certainty of the estimates for the association between saturated fats and all outcomes was very low, mainly because of low precision and high inconsistency (appendix 5). The certainty of the estimates for the association between total trans fats and total CHD and CHD mortality is moderate and very low to low for all others (appendix 6). Insufficient data were available to produce GRADE evidence profiles for industrially produced trans fats and ischemic stroke and ruminant derived trans fats and total CHD and ischemic stroke. These results suggest that further research is likely to have an important effect on our confidence in the estimation of association and could change the estimate.

\section{Discussion}

\section{Principal findings}

In this synthesis of observational evidence we found no clear association between higher intake of saturated fats and all cause mortality, CHD, CHD mortality, ischemic stroke, or type 2 diabetes among apparently healthy adults. Consumption of trans unsaturated fatty acids, however, was associated with a 34\% increase in all cause mortality, a 28\% increased risk of CHD mortal- ity, and a $21 \%$ increase in the risk of CHD. Further, these data suggest that industrial trans fats confer a 30\% increase in the risk of CHD events and an 18\% increase in the risk of CHD mortality. No associations were observed for ruminant trans fat. Because of inconsistency in the included studies, we could not confirm an association between trans fats and type 2 diabetes and found no clear association between trans fats and ischemic stroke. This is the first meta-analysis of prospective observational studies examining associations of saturated and trans fats with all cause mortality and confirms the findings of five previous systematic reviews of saturated and trans fats and CHD. ${ }^{1391-93}$

\section{Saturated fats and health outcomes All cause mortality}

We found no association between saturated fat intake and all cause mortality, the Seven Countries' Study notwithstanding. Controlled trials have shown that when saturated fats replaces carbohydrate in the diet, total and LDL cholesterol increase. ${ }^{94}$ Direct positive associations between total and LDL cholesterol concentrations and all cause and CHD mortality have been shown previously. ${ }^{95-97}$ We found no convincing lack of association with CHD mortality, the major contributor to total mortality. Studies of saturated fats and other major causes of death, such as colon ${ }^{98}$ and breast ${ }^{99}$ cancer, also generally fail to find significant associations. Foods high in saturated fats, particularly processed and red meats, however, have been associated with increased mortality ${ }^{100-102}$ and risk of cancer, ${ }^{103-105}$ though dairy foods are not consistently associated with cancers. ${ }^{106}$ A small body of evidence suggests that saturated fat increases risk of CVD and mortality among people with diabetes. ${ }^{107} 108$ This could relate to the LDL cholesterol raising effect of saturated fat and other metabolic consequences of insulin resistance among people with diabetes. In metabolic studies, saturated fat impairs insulin sensitivity and unsaturated fat improves glucose metabolism; ${ }^{109}$ replacing saturated fat with monounsaturated fat improves lipoprotein and glycemic control in those with type 2 diabetes. ${ }^{110}$

\section{CHD and CHD mortality}

Saturated fats were not associated with total CHD, but we found a trend for association with CHD mortality. Risks associated with higher or lower intakes of macronutrients are sensitive to choice of replacement nutrient(s). In a pooled analysis of 11 prospective cohort studies (not included in our quantitative syntheses to avoid duplication of data), replacement of saturated fats with polyunsaturated fat reduced coronary risk by $13 \%,{ }^{111}$ consistent with results of randomized controlled trials; ${ }^{112-114}$ but replacement of saturated fat with monounsaturated fat or carbohydrate increased the risk of non-fatal myocardial infarction. ${ }^{111}$ In the Pooling Study cohorts, the primary sources monounsaturated fatty acids (MUFA) was animal fat, and some cohorts included trans fats in their definition of MUFA, ${ }^{111}$ so the effect of substitution of saturated fats with MUFA could reflect animal or processed food components not shared 
by plant sources of MUFA (such as olive or canola oils, avocado, and nuts). Carbohydrates in western diets are typically highly processed, high glycemic load foods, which could increase risk when they replace saturated fats. ${ }^{115} 116$ Inconsistent benefit was found for exchanging one food source of saturated fats for another, ${ }^{117} 118$ probably because many saturated fatty acids are common across different food sources.

\section{Ischemic stroke}

We found no association between saturated fats and risk of ischemic stroke, though the relative risk of stroke in the highest compared with the lowest categories of saturated fat exposure was reduced by $18 \%(0.82,95 \%$ confidence interval 0.69 to 0.98 ) in studies conducted in Asian countries. The background saturated fat intake in North American studies was about 12\% (range 9-16\%), while in Asian studies it was about 9\% (range 5-14\%), with Japanese cohorts consistently $<7 \%$, suggesting that the effect of saturated fat might not be uniform across ethnic populations, intake levels, or possibly food sources. ${ }^{61}$ In the multi-center KANWU trial $(n=162)$, a diet high in monounsaturated fat was associated with reduced blood pressure but a diet high in saturated fat was not. ${ }^{119}$

\section{Type 2 diabetes}

We found no association between total saturated fat intake and incident type 2 diabetes. Though saturated fats are believed to compromise insulin sensitivity, ${ }^{120}$ small randomized trials testing this relation yielded inconclusive results. In two larger trials, replacement of saturated fats with either MUFA or carbohydrate improved indices of glucose homeostasis. ${ }^{121} 122$ In the Women's Health Initiative, reducing saturated fat intake from about $13 \%$ of energy to $9.5 \%$ did not reduce type 2 diabetes after 8.1 year follow-up. ${ }^{123}$ Positive associations have been reported between major sources of saturated fats, such as red and processed meat, and development of type 2 diabetes, ${ }^{124} 125$ while inverse associations have been reported for dairy products. ${ }^{126}$

A large (12043 cases) case-cohort study (EPIC-InterAct), ${ }^{127}$ with nearly four million person years of follow-up, prospectively measured individual plasma phospholipid saturated fatty acids at a single time point. It found even-chain saturated fats were positively associated with incident type 2 diabetes (hazard ratios were 1.15 (95\% confidence interval 1.09 to 1.22 ) for 14:0, myristic acid; 1.26 (1.15 to 1.37 ) for $16: 0$, palmitic acid; and 1.06 (1.00 to 1.13) for 8:0, stearic acid per $1 \mathrm{SD}$ ). By contrast, measured odd-chain saturated fats were inversely associated with incident type 2 diabetes (0.79 ( 0.73 to 0.85 ) for $15: 0$, pentadecanoic acid and 0.67 (0.63 to 0.71 ) for 17:0 heptadecanoic acid per $1 \mathrm{SD}$ ).

Odd-chain saturated fats seem to be relatively accurate biomarkers of dairy intake, whereas even chained saturated fats are poor markers of overall dietary intake. ${ }^{128129}$ The findings for odd-chain saturated fats are consistent with an inverse association between dairy products and type 2 diabetes; ${ }^{130}$ although residual confounding by other dairy components such as vitamin D, calcium, or fermentation products could explain this finding. ${ }^{130} 131$ Even-chain saturated fats (such as myristic, palmitic, and stearic acids) originate from de novo lipogenesis from carbohydrates and alcohol in liver or adipose tissue. ${ }^{132133}$ Blood concentrations of these saturated fats, therefore, might not closely match dietary intake of saturated fats. ${ }^{134}$ The association of even-chain fatty acids with type 2 diabetes might reflect the effect of these other dietary components, or other mechanisms that also upregulate de novo lipogenic pathways. Palmitic acid, however, might activate inflammatory cytokines and pose specific lipotoxicity to pancreatic $\beta$ cells. ${ }^{135}$

\section{Trans fat and health outcomes \\ All cause mortality}

Studies in the US and China were the first published cohort studies to report that trans fatty acids are associated with increased all cause mortality, though previous attempts had been made to model the impact of trans fats on mortality. ${ }^{136137}$ In addition to CHD deaths, 44495180 trans fats have been associated with sudden cardiac death ${ }^{138}$ and fatal colon ${ }^{139}$ and breast cancers. ${ }^{140}$ The World Cancer Fund panel, however, found insufficient evidence to implicate trans fats specifically for any type of cancer. ${ }^{106}$ More studies are needed to evaluate the contribution to non-cardiac mortality, which could be examined with data from existing cohorts.

\section{CHD and CHD mortality}

We found reliable and strong positive associations between trans fat intake and CHD and CHD mortality, consistent with several previous systematic reviews and meta-analyses. ${ }^{12} 272993$ The effects on risk of heart disease are mediated via blood lipids and pro-inflammatory processes. ${ }^{141-148}$ Our finding that a $2 \%$ increase in energy from trans fats is associated with a $25 \%$ increased risk of CHD and 31\% increase in CHD mortality (appendix 2 eTables 14-17) is consistent with conclusions of two previous meta-analyses. ${ }^{29} 93$

\section{Ischemic stroke}

The two prospective studies that assessed the association between trans fats and ischemic stroke yielded inconsistent results. One study in men showed no association with stroke; 65 the other, in women, showed a positive association in those who did not take aspirin. ${ }^{69}$ Further the association with trans fats was significant only for lacunar stroke, with a trend for hemorrhagic stroke but not for stroke of cardioembolic origin. A nested case-control study conducted within the Women's Health Initiative Observational Study (WHI-OS) with 10 year follow-up ${ }^{149}$ found no association between serum total trans 16:1, 18:1, or 18:2 and ischemic stroke; these results were not included in our quantitative synthesis because the different trans fats reported could not be classified as "total" or strictly "industrial" or "ruminant" derived. The association with risk of stroke requires further study. 


\section{Type 2 diabetes}

We found no association between trans fats and type 2 diabetes, though the interpretation of this finding is complicated by heterogeneity. Inconsistency has also been noted in randomized trials of the effects on glucose homeostasis. ${ }^{150}$ Two cohort studies reporting strong associations between trans fats and type 2 diabetes $^{7374}$ were generally similar to those that did not with respect to measures of exposures, outcomes, and most covariates, except that the three studies that failed to show an association adjusted for fiber and magnesium, ${ }^{727576}$ which might protect against diabetes, ${ }^{151} 152$ while the two studies that showed an association ${ }^{7374} \mathrm{did}$ not. Pooling estimates without adjustment for magnesium and fiber yields a 16\% increased risk of type 2 diabetes with high trans fat intake (four studies; risk ratio $1.16,95 \%$ confidence interval 0.95 to $1.41 ; \mathrm{I}^{2}=82 \%$; $\left.\mathrm{P}_{\text {het }}<0.001\right)$; when we limited analysis to the three studies with no serious risks of bias, ${ }^{737476}$ this became a $28 \%$ increased risk (three studies; $1.28,1.16$ to $1.41 ; \mathrm{P}<0.001$; $\left.\mathrm{I}^{2}=0 \% ; \mathrm{P}_{\text {het }}=0.87\right)$.

The role of trans-palmitoleic acid in prevention of type 2 diabetes could represent an important new direction for fatty acid research. It is important to note, however, that the exposure levels to this nutrient are typically low. In the three included studies, trans-palmitoleic acid represented $<1 \%$ of total fatty acid intake, with the mean reported exposure level varying about eightfold across cohorts (mean $0.06 \%$ to $0.49 \%$ of plasma phospholipid fatty acids), with considerable variability within the cohort (SD ranging from $0.03 \%$ to $0.20 \%$ ). Nevertheless, the protective associations with type 2 diabetes are quite consistent $\left(\mathrm{I}^{2}=30 \%\right)$ and compatible with a $26-54 \%$ reduction in risk across an estimated threefold intake range. The biology of a potential protective effect of trans-palmitoleic acid against type 2 diabetes could relate to its ability to mimic the role of cis-palmitoleic acid, which is protective against diabetes in animals. ${ }^{153}$

\section{Industrially produced $v$ ruminant derived trans fats}

Consistent with the findings of a previous meta-analysis of observational studies, ${ }^{12}$ our study, which included recent data from a large Norwegian study, ${ }^{83}$ found that industrially produced, but not ruminant derived, trans fats are associated with risk of CHD. This might reflect a true difference between sources or might be a function of consumption levels. Ruminant derived trans fats are consumed at relatively low levels in most populations; in the studies included in our present analysis, the average intake of industrially produced trans fats was about 2.5 -fold that of ruminant derived trans fats (mean energy intakes of about $1.8 \%$ (range about $0.3-3.7 \%$ ) and $0.7 \%(0.6-0.8 \%)$, respectively). The greater range of intake of industrially produced trans fats in cohort studies provides greater statistical power for detection of associations.

Two quantitative syntheses of randomized controlled trials of ruminant derived trans fats and biomarkers of cardiovascular risk arrived at opposite conclusions. Brouwer and colleagues pooled six randomized controlled trials of ruminant derived trans fats and 29 of industrially produced trans fats and found that both had similar impacts on LDL:HDL cholesterol when they were consumed across an equivalent intake range $(0.7-6.6 \%$ of energy), ${ }^{13}$ which supports the notion that the lack of association of ruminant derived trans fats with cardiovascular outcomes in the present and previous analyses $^{12}$ is related to their lower intake levels. Gayet-Boyer and colleagues, however, pooled 13 randomized controlled trials (including all of those included by Brouwer and colleagues) and found no linear association between ruminant derived trans fats and LDL:HDL cholesterol or total:HDL cholesterol across a dose range of $0.1-4.2 \%$ of energy. ${ }^{154}$ The reasons for this discrepancy are unclear but could relate to differences in the approaches taken to the quantitative synthesis (such as study weighting, regression modeling) or inclusion criteria (such as minimum duration of studies, acceptable choice of comparison arms). Further research is required to assess the impact of ruminant derived versus industrially produced trans fats on health outcomes; but the best available observational evidence suggests that at the reported intake levels in the included studies, ruminant trans fats do not increase the risk of developing the health outcomes reviewed here.

In support of the importance of exposure levels, case-control studies in Costa Rica and Australia found that the association between total trans fats and CHD was attenuated after removal of industrially produced trans fats from the food supply, ${ }^{155}{ }^{156}$ which resulted in lower levels of consumption of total trans fats, primarily consisting of ruminant derived trans fats. Case-control studies have shown a strong association between trans18:2 isomers, ${ }^{155}$ 157-161 abundant in partially hydrogenated oils, and CHD (six studies, seven comparisons; multivariable odds ratio $1.82,95 \%$ confidence interval 1.14 to 2.90; $\mathrm{P}=0.01 ; \mathrm{I}^{2}=77 \% ; \mathrm{P}_{\text {het }}<0.001$; appendix 4 eFigure 43) but no significant association between trans-18:1 isomers, ${ }^{155157-162}$-derived principally from partially hydrogenated oils, but also found in ruminant foods-and CHD (seven studies, eight comparisons; 1.19, 0.93 to 1.51; $\mathrm{P}=0.16 ; \mathrm{I}^{2}=59 \% ; \mathrm{P}_{\text {het }}=0.02$; appendix 4 eFigure 44).

A community based 10 year prospective cohort study of older adults (the Cardiovascular Health Study, US) ${ }^{149}$ measured the association between phospholipid concentrations of specific trans fatty acids found chiefly in prepared foods ${ }^{163}$ (trans-16:1n9, trans-18:2 (trans/cis-18:2; cis/trans-18:2; and trans/trans-18:2), and trans-18:1) and all cause death and deaths from CHD and CVD. Circulating trans/trans- and trans/cis-18:2 were generally harmful, but variation existed across classes, with a noteworthy lack of association for trans-18:1, the major component of partially hydrogenated vegetable oils. Of public health importance is that commercially produced trans fatty acids other than trans-18:1 can remain in the food supply even after removal of partially hydrogenated oils, via vegetable oil deodorization and high temperature frying. ${ }^{164-166}$ Future work is needed to assess the public health importance of this residual risk.

Methodological issues related to measuring intake of a nutrient at such low levels ( $<1 \%$ of energy), and the complexity of parsing specific trans fatty acids into "industrial" or "ruminant" sources, also decreases our 
confidence in the results for ruminant derived trans fats. With the phasing out of industrially produced partially hydrogenated oils in several countries, future prospective studies might be better positioned to assess the effects of ruminant derived trans fats on health. Based on currently available data from prospective cohort studies, ruminant derived trans fats are not associated with risk of CHD, though it is uncertain whether this a true biological difference or a function of their lower levels of intake during the periods of study.

In a post hoc sensitivity analysis, we estimated the effect of total trans fats on CHD mortality and total CHD at levels similar to those reported in the studies of ruminant trans fats included in the analysis, to help to assess whether the generally low exposure levels to ruminant trans fatty acids were driving the lack of association observed for these outcomes in the ruminant trans fat analysis. To do so, we pooled the multivariable relative risks for quantiles that most closely approximated a $0.8 \%$ of energy increase from the referent category for total trans fat and CHD mortality; and a 1.2\% of energy increase from the referent category for total trans fat and CHD. In this sensitivity analysis, for total trans fats and CHD mortality, the risk ratio was 1.02 (five studies, six comparisons; 95\% confidence interval 0.90 to 1.16; $\mathrm{P}=0.73 ; \mathrm{P}_{\text {het }}=0.25$; $\mathrm{I}^{2}=24 \%$; appendix 4 eFigure 45; exposure estimates in appendix 2 eTable 20) or 1.03 when we added unpublished studies (seven studies, nine comparisons; 0.95 to $1.12 ; \mathrm{P}=0.45 ; \mathrm{P}_{\text {het }}=0.36 ; \mathrm{I}^{2}=9 \%$; appendix 4 eFigure 46). For total trans fats and CHD, the risk ratio was 1.17 (six studies, seven comparisons; 1.07 to 1.29; $\mathrm{P}<0.001 ; \mathrm{P}_{\text {het }}=0.41 ; \mathrm{I}^{2}=1 \%$; appendix 4 eFigure 47).

\section{Consistency across observational designs}

Findings in prospective cohorts were generally consistent with those from case-control studies, which found that higher exposure to trans fats (whether measured by food frequency questionnaire or biomarker) was associated with a 51\% increased odds of CHD (odds ratio 1.51, 95\% confidence interval 1.08 to 2.09; $\mathrm{P}=0.01 ; \mathrm{I}^{2}=75 \%$; $\left.\mathrm{P}_{\text {het }}<0.001\right)$. This was attenuated and no longer significant when we restricted the synthesis to high quality studies (1.37, 0.78 to 2.41; $\mathrm{P}=0.28 ; \mathrm{I}^{2}=78 \% ; \mathrm{P}_{\text {het }}<0.001$ ) (appendix 4 eFigures 45-47). Inclusion of nested case-control studies ${ }^{167-172}$ in meta-analyses of prospective studies of total trans fats and CHD mortality (appendix 4 eFigure 48), CHD (appendix 4 eFigure 49), type 2 diabetes (appendix 4 eFigure 50) did not substantively alter the pooled association from the association derived from prospective cohort studies. Nested case-control studies with biomarkers of saturated fat intake (such as erythrocyte or adipose tissue) collected before occurrence of disease, though few in number, consistently found that people with highest levels of exposure to saturated fat were at increased risk of CHD mortality, total CHD, and type 2 diabetes, and these methods of exposure measurement are less subject to bias. Pooling of prospective cohorts with nested case-control studies of saturated fats resulted in a borderline significant association with CHD mortality but not total CHD or type 2 diabetes (appendix 4 eFigures 51-53). Prospective studies with repeated biomarker assessments will advance knowledge in this area.

\section{Strengths and weaknesses of the study}

This study has several strengths. First, we assessed confidence in the estimates with GRADE to facilitate guideline development. Second, studies were identified through a systematic search of the literature, augmented with manual searches of reference lists of published papers and systematic reviews. Third, the quantitative synthesis focused on studies measuring comparable outcomes with similar designs, reducing methodological heterogeneity.

There were, however, important limitations related to evidence synthesis and quality. First, meta-analytic techniques depend on the availability of conceptually similar and combinable effect estimates across studies. If such estimates are not available, the ability to pool all available and relevant data in a meaningful way is compromised, and the pooled estimate of effect might be suboptimal. Notably, in our evidence synthesis, the positive association between saturated fat and total mortality observed in the Seven Countries' Study ${ }^{38}$ could not be combined with other association estimates because the $\beta$ coefficient could not be directly converted into an estimate of relative risk. The GRADE approach offers a methodological advance in evaluating the quality of the body of evidence in a transparent fashion, and thus a "non-combinable" estimate can still inform our judgment of the presence, strength, and direction of an effect. Therefore, because of this inconsistency, we document the inconsistency between this finding (positive) and that of the pooled prospective cohort studies (null), and rate the confidence we have in a true quantitative "null” association as "very low."

Second, observational studies cannot provide causal evidence of an effect of saturated or trans fatty acids on the development of health outcomes examined; they can describe only associations. Measurement error is often serious in epidemiologic studies of diet and disease, which can bias such associations towards the null. Major limitations of the included studies are described in appendix 2 eTables $3 \mathrm{a}$ and $3 \mathrm{~b}$ (Newcastle-Ottawa evaluations) and in the footnotes to the GRADE tables (appendices 5 and 6). These include unrepresentative cohorts or a vaguely defined cohort sampling frame; misclassification of exposure from inaccurate measurement tools (selection and exposure measurement biases); failure to account for major confounders such as age, socioeconomic status, smoking, total energy, or family history (non-comparability biases); and lack of validated outcome measures or insufficient study duration to observe a high number of events (outcome assessment biases). Additionally, random error can attenuate the observed associations between trans fats and health outcomes and also explain the lack of association between saturated fat and health outcomes. This error can arise from several sources, including residual confounding, recall bias, and exposure misclassification.

The reviewed studies typically relied on food frequency questionnaires, 24 hour recalls, or seven day food records, each of which has serious limitations in 
their ability to accurately capture long term dietary fat intake. Tissue levels of saturated fat are not always valid measures of dietary saturated fat, and associations based on these exposure measures are difficult to interpret because of shared endogenous and exogenous sources. Exposure measurement error is potentially more serious with trans fatty acids, though analytical methods for determining trans fatty acid content of foods and tissues, and differentiating ruminant derived from industrially produced trans fatty acids, has evolved considerably since $1980 .{ }^{173}$ It is difficult to classify trans fat isomers as ruminant or industrial because of shared food sources, and self reported intakes can be incorrect because of outdated food databases and the rapidly changing trans fat content of foods. These limitations are especially important given that during the timeframe of the studies reviewed most countries were making major efforts to remove trans fats from the food supply.

Third, several investigators adjusted for changes in risk factors on the causal pathway between diet and disease, serum lipids and blood pressure, which attenuates relations between saturated or trans fats and the outcomes. The validity of use of "most adjusted" models, which account both for potential confounders and causal intermediates, has been debated. ${ }^{174} 175$ Models adjusted for potential confounders and intermediate variables underestimate associations because of over-controlling for the effect of causal intermediates; unadjusted models overestimate associations because estimates reflect other determinants of the health outcomes. Comparability across studies is compromised when different studies include different sets of confounders. To assess the potential impact of over-adjustment, we assessed "intermediately adjusted models"-that is, those that adjusted for the most relevant confounders (smoking, age, sex, and total energy) but not potential causal intermediates (blood pressure or anti-hypertensive drugs, serum lipids or lipid lowering drugs)-for associations for which we had a high number of studies: saturated fat and cardiovascular outcomes. In these sensitivity analyses, the adjusted risk ratio was 1.21 (95\% confidence interval 0.93 to 1.58; eight studies) for saturated fat and CHD mortality; 1.05 (0.93 to 1.19; 11 studies) for saturated fat and total CHD; and 0.87 ( 0.76 to 1.00 , two studies) for saturated fat and ischemic stroke. These figures would not meaningfully change our conclusions based on the fully adjusted models.

Fourth, although we carried out extensive subgroup analyses with meta-regression, the substantial heterogeneity present in most analyses for saturated fats remains unexplained.

Fifth, because of a small number of cohorts, dose-response relations, or differences between specific sources of saturated or trans fatty acids on health outcomes, were not robustly quantified. We had insufficient data to perform robust subgroup analyses for trans fatty acids associations. In post hoc sensitivity analyses presenting highest versus lowest intakes only in those studies where the referent group had an estimated trans fat intake $<1 \%$ of energy, or a highest intake $\geq 1 \%$ of energy, provided results consistent with the main analyses (appendix 2 eTables 18 and 19; appendix 4 eFigures 54-62).

\section{Strengths and weaknesses in relation to other studies}

This is the seventh systematic review and meta-analysis of observational studies of saturated and/or trans fats and health outcomes in the past 10 years. ${ }^{13129193141176}$ Our work updates and corroborates previous systematic reviews and meta-analyses of observational studies that have also failed to find associations between saturated fat and CVD, ${ }^{1}$ total CHD, ${ }^{139193}$ fatal CHD, ${ }^{193}$ and stroke; ${ }^{3}$ positive associations between trans fat and total CHD ${ }^{129193141}$ and fatal CHD; ${ }^{1293}$ and no association with type 2 diabetes. ${ }^{176}$ A Cochrane review of randomized trials of reduced saturated fats and cardiovascular events found a $17 \%$ reduced risk with lower saturated fat intake (risk ratio 0.83, 95\% confidence interval 0.72 to $0.96 ; 13$ studies with 53300 participants; moderate GRADE). ${ }^{8}$ Methodological advantages of randomized controlled trials over prospective cohort studies include the balancing of known and unknown confounders and better measurement and finer control of dietary fat levels.

\section{Limitations of comparison of extremes}

Our a priori research question was to examine the effect on the health outcomes of higher compared with lower saturated fat, which we did by comparing highest and lowest intake estimates. Such a comparison, however, obscures the importance of reciprocal and possibly heterogeneous decreases in other macronutrients that accompany high saturated or trans fat intakes. Thus, an overarching consideration is that the effect estimate of higher intakes of saturated or trans fats on health outcomes is linked to the nutrient that it replaces. Most studies in the present review did not explicitly model the effects of nutrient substitution, but when total energy, protein, and alcohol are covariates in the multivariable model, coefficients for fat reflect substitution of saturated or trans fat for carbohydrate. Indeed, carbohydrate energy was typically lowest in those in the highest intakes of saturated and trans fat. Common sources of carbohydrate in typically studied populations were highly processed high glycemic load foods, ${ }^{115}$ which can increase risk of CHD independently of saturated and trans fats through different metabolic pathways; likely attenuating the observed associations between these fats and outcomes. ${ }^{177}$

\section{Replacement of saturated fats by high quality carbohydrate}

The analysis of data from the largest prospective study to examine carbohydrate quality, as measured by glycemic index, suggests that replacement of saturated fat with high glycemic index carbohydrate increased the risk of CVD, but replacement with low glycemic index carbohydrate (such as whole fruits, vegetables, pulses, and grains) decreased risk. ${ }^{116}$

\section{Replacement of saturated fats by unsaturated fats} In cohort studies that have directly modeled substitution effects, replacement of saturated fat by polyunsaturated fat (with a corresponding increase in polyunsaturated: 
saturated (P:S) ratio conferred the greatest reduction in risk of CVD; ${ }^{111}$ though these studies did not distinguish between $n-3$ and $n-6$ fatty acids as the replacement choice. Several intervention studies that have replaced saturated fat with polyunsaturated fats achieved relatively high P:S ratios ( $>1.0$ to about 2.5) through replacement of saturated fat with predominantly soybean ( $n-6$ linoleic) and marine oils ( $n-3$ eicosapentaenoic and docosahexaenoic acids from sardines). At these levels significant CHD benefits were seen, ${ }^{112-114}$ consistent with the finding that favorable effects of diets with reduced saturated fat on cardiovascular risk might depend on a significant reciprocal increase in polyunsaturated fat ${ }^{92}$ or high quality carbohydrate from whole fruits, vegetables, pulses, and grains, which tend to have a lower glycaemic index. ${ }^{116}$ In a meta-analysis of cohort studies, replacement of 5\% of energy from saturated fat with linoleic acid ( $n$-6 PUFA) was associated with a 9\% lower risk of CHD events (risk ratio 0.91, 95\% confidence interval 0.87 to 0.96 ; 13 studies with 310602 participants) and a 13\% lower risk of CHD deaths (0.87, 0.82 to 0.94). ${ }^{178}$ A re-analysis of the Sydney Diet Heart Study and updated meta-analysis, however, found no benefit and possible harm associated with replacement of saturated fat by linoleic acid (hazard ratio 1.33 (95\% confidence interval 0.99 to 1.79) for CHD death and 1.27 (0.98 to 1.65) for CVD) in secondary prevention trials. ${ }^{179}$ Replacement of saturated fat with monounsaturated fat or carbohydrate was not associated with significant reduction in CHD risk but was associated with a small increase in risk of non-fatal myocardial infarction. ${ }^{115}$ The relative risks associated with different saturated fats or their food sources were not importantly different, with the exception of a single study that noted replacement of saturated fat from meat with saturated fat from dairy decreased risk of CVD. ${ }^{118}$ Other components of these foods, however, could also be responsible for these effects.

\section{Replacement of trans fats by carbohydrate}

In the two studies that directly assessed the impact on type 2 diabetes of replacement of carbohydrate with trans fat, replacement of $1 \%$ of energy from carbohydrate with trans fatty acids was associated with a $23 \%$ increased risk (hazard ratio 1.23, 95\% confidence interval 1.02 to 1.48$)^{73}$ and replacement of $2 \%$ of energy from carbohydrate with trans fatty acids was associated with a $39 \%$ increased risk $(1.39,1.15$ to 1.67$) .^{72}$ In the two studies that directly assessed the impact of replacement of carbohydrate with trans fats, ${ }^{6468}$ replacement was associated with either no increased risk of stroke in men (risk ratio $0.86,0.55$ to 1.32 , per $2 \%$ of energy) ${ }^{64}$ or a small but significant increase risk of stroke in older post-menopausal women $\left(1.08,1.004\right.$ to 1.16 , per $2 \mathrm{~g}$ of intake) ${ }^{68}$

\section{Replacement of trans fat by unsaturated fats}

Using data from two of the largest prospective cohort studies, Mozaffarian and Clarke ${ }^{28}$ reported the adjusted risk ratio of CHD for isocaloric replacement of $2 \%$ of energy from trans unsaturated fatty acids with saturated fatty acids, monounsaturated fatty acids, or polyunsaturated fatty acids. They found that replacement of $2 \%$ of energy from trans fats with saturated fat would reduce risk by $17 \%$ (risk ratio $0.83,95 \%$ confidence interval 0.75 to 0.93$)$. The reductions in risk were $21 \%(0.79,0.70$ to 0.88 ) for replacement with monounsaturated fat and $24 \%(0.76,0.67$ to 0.85$)$ for replacement with polyunsaturated fat. In the present analysis, we found no new evidence that would substantially alter these risks.

\section{Meaning of the study}

This systematic review and meta-analysis of evidence from large generally well designed observational studies does not support a robust association of saturated fats with all cause mortality, CHD, CHD mortality, ischemic stroke, or diabetes in healthy individuals; but the choice of comparison nutrient ( $n-6$ and/or $n-3$ PUFA, MUFA, refined or high quality carbohydrate) must be carefully considered. Few observational studies, however, modeled the effect of replacing saturated or trans fats with other nutrients. In large prospective studies, when polyunsaturated fats replace saturated fats, risk of CHD is reduced but not when MUFA or carbohydrate is the replacement choice. Higher, compared with lower, intakes of trans fats are associated with a 20-30\% increased risk of all cause mortality, CHD and CHD mortality, regardless of choice of replacement nutrient, but associations with type 2 diabetes and stroke are unclear. The association seems to be most consistently driven by industrially produced trans fats, probably because of their higher intakes among participants during the follow-up periods of the included studies. Dietary guidelines for saturated and trans fatty acids must carefully consider the effect of replacement nutrients.

\section{Unanswered questions and future research}

Several questions could not be answered by our review. First, do different sources (for example, animal $v$ plant) and chain lengths (odd $v$ even) of saturated fat have different effects on health, particularly with respect to risk of diabetes? The current evidence reviewed suggests that dairy fats, specifically odd chained saturated fatty acids, might be protective against type 2 diabetes; but, apart from recommendations for broad sources of fatty acids (such as dairy $v$ plant $v$ animal flesh), it is not feasible to separate different types of saturated fats with respect to food choices because the foods contain a combination of several saturated fats. Second, what is the impact of saturated fats consumed in the context of diverse background diets on health? Notably, the association between certain foods and CHD cannot be predicted solely by their content of total saturated fats because individual saturated fats might have different cardiovascular effects, and major food sources of saturated fat contain other constituents that could influence risk of CHD. Third, are there meaningful differences in the choice of polyunsaturated fat-for instance, $n-3$ or $n-6$-that replaces saturated (or trans) fats in the diet? Current evidence suggests that either group of polyunsaturated fats provide similar benefit. Fourth, is the reported protective effect of trans-palmitoleic acid for type 2 diabetes robust, and, if so, does the apparent benefit extend to cardiovascular disease outcomes? Fifth, do threshold levels of ruminant trans fatty acid 
intakes exist, above which cardiovascular risk increases in a similar fashion to that seen with industrial trans fatty acids? Finally, what should be the "gold" standard for measurement of fatty acid intake? Development of reliable and valid methods of assessing fatty acid intakes in large longitudinal cohort studies with sufficient follow-up to observe clinical events and deaths must remain a priority to improve the quality of the evidence on which dietary advice is based.

We are grateful to Viranda Jayalath (University of Toronto) for his assistance developing the data abstraction forms. We thank Paul Knekt, Anthony Hanley, and Ingrid Santaren for providing data, and Hannia Campos, and Kay-tee Khaw for clarifying aspects of their studies; Christine Neilson and Natalie Campbell for their assistance with the literature search; Michael Zulyniak for assistance with preparing the manuscript for publication; and the members of the WHO Nutrition Guidance Advisory Group (NUGAG) Subgroup on Diet and Health for their helpful comments on the draft results. WHO agreed to the publication of this systematic review in a scientific journal because it serves as the background evidence review for updating WHO guidelines on saturated and trans fatty acids and should therefore be available widely. We appreciate the helpful comments of peer reviewers Arne Atrup, Ronald Krauss, JM Chardigny, and Evangeline Mantzioris, which have greatly improved the quality of the manuscript.

Contributors: Study concept and design: RJdeS, SSA, JB, AMe. Development and implementation of literature search strategy: EU, TK. Acquisition of data, including review of literature search results and data abstraction: RJdeS, EU, TK, AMe, AMa, AIC, VH, PB. Analysis and interpretation of data: RJdeS, AMe, SSA, JB, HS. Drafting of the manuscript: RJdeS, AMe, VH, AIC. Critical revision of the manuscript for important intellectual content: all authors. Statistical analysis: RJdeS, JB. Administrative, technical, and material support: EU, TK, AM. Study supervision: SSA, JB. RJdeS is guarantor.

Funding: This study was funded by WHO, which defrayed costs associated with preparing the draft manuscript, including information specialist and technical support and article retrieval costs. This systematic review was presented by RJdeS at the 5 th Nutrition Guidelines Advisory Group (NUGAG) meeting in Hangzhou, China (4-7 March, 2013), the 6th NUGAG meeting in Copenhagen, Denmark (21-24 Oct, 2013), and the 7th NUGAG meeting in Geneva, Switzerland (9-12 Sept, 2014); and via skype during the 8th NUGAG meeting in Fukuoka, Japan (9-12 June, 2015). WHO covered travel and accommodation costs for RJdeS to attend these meetings. The research questions for the review were discussed and developed by the WHO Nutrition Guidance Expert Advisory Group (NUGAG) Subgroup on Diet and Health and the protocol was agreed by the WHO NUGAG Subgroup on Diet and Health; however, neither WHO nor the WHO NUGAG Subgroup on Diet and Health had any role in data collection or analysis.

Competing interests: All authors have completed the Unified Competing Interest form at www.icmje.org/coi disclosure.pdf (available on request from the corresponding author) and declare: RJdeS has received a Canadian Institutes for Health Research (CIHR) postdoctoral fellowship. VH has received a Province of Ontario graduate scholarship and research support from the Canadian Institutes of Health Research (CIHR). AIC has received a Province of Ontario graduate scholarship.

Ethical approval: Not required.

Transparency statement: RJdeS affirms that the manuscript is an honest, accurate, and transparent account of the study being reported; that no important aspects of the study have been omitted; and that any discrepancies are disclosed.

Data sharing: The full dataset and statistical code are available from the corresponding author.

This is an Open Access article distributed in accordance with the Creative Commons Attribution Non Commercial (CC BY-NC 4.0) license, which permits others to distribute, remix, adapt, build upon this work non-commercially, and license their derivative works on different terms, provided the original work is properly cited and the use is non-commercial. See: http://creativecommons.org/licenses/ by-nc/4.0/.

1 Chowdhury R, Warnakula S, Kunutsor S, et al. Association of Dietary, Circulating, and Supplement Fatty Acids With Coronary RiskA Systematic Review and Meta-analysis. Ann Intern Med 2014:160:398-406.
2 Harcombe Z, Baker JS, Cooper SM, et al. Evidence from randomised controlled trials did not support the introduction of dietary fat guidelines in 1977 and 1983: a systematic review and meta-analysis. Open Heart 2015;2:e000196.

3 Siri-Tarino PW, Sun Q, Hu FB, Krauss RM. Meta-analysis of prospective cohort studies evaluating the association of saturated fat with cardiovascular disease. Am / Clin Nutr 2010:91:535-46.

4 Health Canada, Statistics Canada, Canadian Community Health Survey. Nutrient Intakes from Food: Provincial, Regional and National Data Tables (CCHS Cycle 2.2)Vol 1-3. Health Canada Publications, 2009.

5 Wright JD, Wang CY, Kennedy-Stephenson J, Jacobs Jr DR, Ervin RB.Dietary intakes of ten key nutrients for public health: 1999-2000. National Center for Health Statistics, 2003.

6 Siri-Tarino PW, Sun Q, Hu FB, Krauss RM. Saturated fatty acids and risk of coronary heart disease: modulation by replacement nutrients. Curr Atheroscler Rep 2010;12:384-90.

7 Mozaffarian D, Micha R, Wallace S. Effects on coronary heart disease of increasing polyunsaturated fat in place of saturated fat: a systematic review and meta-analysis of randomized controlled trials. PLoS Med 2010:7:e1000252.

8 Hooper L, Martin N, Abdelhamid A, Davey Smith G. Reduction in saturated fat intake for cardiovascular disease. Cochrane Database Syst Rev 2015;6:CD011737.

9 Doell D, Folmer D, Lee H, Honigfort M, Carberry S. Updated estimate of trans fat intake by the US population. Food Addit Contam Part A Chem Anal Control Expo Risk Assess 2012;29:861-74

10 Kris-Etherton PM, Lefevre M, Mensink RP, Petersen B, Fleming J, Flickinger BD. Trans fatty acid intakes and food sources in the U.S. population: NHANES 1999-2002. Lipids 2012;47:931-40.

11 Ratnayake WM, L'Abbe MR, Farnworth S, et al. Trans fatty acids: current contents in Canadian foods and estimated intake levels for the Canadian population. J AOAC Int 2009;92:1258-76.

12 Bendsen NT, Christensen R, Bartels EM, Astrup A. Consumption of industrial and ruminant trans fatty acids and risk of coronary heart disease: a systematic review and meta-analysis of cohort studies. Eur J Clin Nutr 2011;65:773-83.

13 Brouwer IA, Wanders AJ, Katan MB. Effect of animal and industrial trans fatty acids on HDL and LDL cholesterol levels in humans-a quantitative review. PLoS One 2010;5:e9434.

14 Eckel RH, Jakicic JM, Ard JD, et al. 2013 AHA/ACC guideline on lifestyle management to reduce cardiovascular risk: a report of the American College of Cardiology/American Heart Association Task Force on Practice Guidelines. J Am Coll Cardiol 2014;63:2960-84.

$15 \mathrm{FAO} / \mathrm{WHO}$. Fats and fatty acids in human nutrition: report of an expert consultation. FAO, 2010

16 Lichtenstein AH, Appel LJ, Brands M, et al. Diet and lifestyle recommendations revision 2006: a scientific statement from the American Heart Association Nutrition Committee. Circulation 2006;114:82-96.

17 US Department of Agriculture and US Department of Health and Human Services. Dietary Guidelines for Americans, 2010. 7th ed. US Government Printing Office, 2010.

18 EFSA Panel on Dietetic Products NaA. Scientific opinion on dietary reference values for fats, including saturated fatty acids, polyunsaturated fatty acids, monounsaturated fatty acids, trans fatty acids, and cholesterol. EFSA / 2010;8:1461.

19 Food Standards Australia New Zealand. Trans fatty acids. www. foodstandards.gov.au/consumer/nutrition/transfat/Pages/default.aspx.

20 Guyatt GH, Oxman AD, Vist GE, et al. GRADE: an emerging consensus on rating quality of evidence and strength of recommendations. $B M$ J 2008;336:924-6

21 Guyatt G, Oxman AD, Akl EA, et al. GRADE guidelines: 1. IntroductionGRADE evidence profiles and summary of findings tables. I Clin Epidemiol 2011;64:383-94

22 Guyatt GH, Oxman AD, Schunemann HJ, Tugwell P, Knottnerus A. GRADE guidelines: a new series of articles in the Journal of Clinical Epidemiology. J Clin Epidemiol 2011;64:380-2.

23 World Health Organization. WHO handbook for guideline development. http://apps.who.int/iris/ bitstream/10665/75146/1/9789241548441_eng.pdf.

24 Higgins JPT, Green S. Cochrane handbook for systematic reviews of interventions. www.cochrane-handbook.org.

25 Stroup DF, Berlin JA, Morton SC, et al. Meta-analysis of observational studies in epidemiology: a proposal for reporting. Meta-analysis of Observational Studies in Epidemiology (MOOSE) group. JAMA 2000:283:2008-12.

26 Gebauer SK, Chardigny JM, Jakobsen MU, et al. Effects of ruminant trans fatty acids on cardiovascular disease and cancer: a comprehensive review of epidemiological, clinical, and mechanistic studies. Adv Nutr 2011:2:332-54.

27 Wang T, Cai MQ. Meta-analysis of risk of trans fatty acids on coronary heart diseases. Shanghai Jiao Tong Da Xue Xue Bao Yi Xue Ban 2011;31:1164-69.

28 Mozaffarian D, Clarke R. Quantitative effects on cardiovascular risk factors and coronary heart disease risk of replacing partially hydrogenated vegetable oils with other fats and oils. Eur J Clin Nutr 2009:63:S22-S33. 
29 Mozaffarian D, Aro A, Willett WC. Health effects of trans-fatty acids: Experimental and observational evidence. Eur J Clin Nutr 2009:63:S5-S21.

30 Wells GA, Shea B, O'Connell D, et al. The Newcastle-Ottawa Scale (NOS) for assessing the quality of nonrandomised studies in meta-analyses. www.ohri.ca/programs/clinical_epidemiology/oxford. asp.

31 DerSimonian R, Laird N. Meta-analysis in clinical trials. Control Clin Trials 1986;7:177-88.

32 Higgins JP, Thompson SG, Deeks JJ, Altman DG. Measuring inconsistency in meta-analyses. BMJ 2003;327:557-60.

33 Borenstein M, Hedges LV, Higgins JPT, Rothstein HR. Introduction to meta-analysis. John Wiley, 2008.

34 Thompson SG, Higgins JP. How should meta-regression analyses be undertaken and interpreted? Stat Med 2002;21:1559-73.

35 Greenhouse JB, Iyengar S. Sensitivity analysis and diagnostics. In: Cooper HM, Hedges LV, Valentine IC, eds. The handbook of research synthesis and meta-analysis. 2nd ed. Russell Sage Foundation, 2009:423-24.

36 Sterne JA, Gavaghan D, Egger M. Publication and related bias in meta-analysis: power of statistical tests and prevalence in the literature. J Clin Epidemiol 2000;53:1119-29.

37 Duval S, Tweedie R. Trim and fill: a simple funnel-plot-based method of testing and adjusting for publication bias in meta-analysis. Biometrics 2000;56:455-63.

38 Kromhout D, Bloemberg B, Feskens E, Menotti A, Nissinen A Saturated fat, vitamin $\mathrm{C}$ and smoking predict long-term population all-cause mortality rates in the Seven Countries Study. Int J Epidemiol 2000;29:260-5.

39 Leosdottir M, Nilsson PM, Nilsson JA, Mansson H, Berglund G. Dietary fat intake and early mortality patterns - data from The Malmo Diet and Cancer Study. J Intern Med 2005;258:153-65.

40 Mann JI, Appleby PN, Key TJ, Thorogood M. Dietary determinants of ischaemic heart disease in health conscious individuals. Heart 1997;78:450-5.

41 Tucker KL, Hallfrisch J, Qiao N, Muller D, Andres R, Fleg JL. The combination of high fruit and vegetable and low saturated fat intakes is more protective against mortality in aging men than is either alone: the Baltimore Longitudinal Study of Aging. J Nutr 2005;135:556-61.

42 Chien KL, Lin HJ, Hsu HC, et al. Comparison of predictive performance of various fatty acids for the risk of cardiovascular disease events and all-cause deaths in a community-based cohort. Atherosclerosis 2013;230:140-7.

43 Wakai K, Naito M, Date C, Iso H, Tamakoshi A, Group IS. Dietary intakes of fat and total mortality among Japanese populations with a low fat intake: the Japan Collaborative Cohort (JACC) Study. Nutr Metab (Lond) 2014:11:12.

44 Ascherio A, Rimm EB, Giovannucci EL, Spiegelman D, Stampfer M, Willett WC. Dietary fat and risk of coronary heart disease in men: cohort follow up study in the United States. BMJ 1996;313:84-90.

45 Boniface DR, Tefft ME. Dietary fats and 16-year coronary heart disease mortality in a cohort of men and women in Great Britain. Eur J Clin Nutr 2002;56:786-92.

46 Esrey KL, Joseph L, Grover SA. Relationship between dietary intake and coronary heart disease mortality: lipid research clinics prevalence follow-up study. J Clin Epidemiol 1996;49:211-6

47 Goldbourt U, Yaari S, Medalie JH. Factors predictive of long-term coronary heart disease mortality among 10,059 male Israeli civil servants and municipal employees. A 23-year mortality follow-up in the Israeli Ischemic Heart Disease Study. Cardiology 1993;82:100-21.

48 Kushi LH, Lew RA, Stare FJ, et al. Diet and 20-year mortality from coronary heart disease. The Ireland-Boston Diet-Heart Study. N Engl Med 1985;312:811-8.

49 Pietinen P, Ascherio A, Korhonen P, et al. Intake of fatty acids and risk of coronary heart disease in a cohort of Finnish men. The AlphaTocopherol, Beta-Carotene Cancer Prevention Study. Am J Epidemiol 1997; 145:876-87.

50 Shekelle RB, Shryock AM, Paul O, et al. Diet, serum cholesterol, and death from coronary heart disease. The Western Electric study. N Engl J Med 1981;304:65-70

51 Xu J, Eilat-Adar S, Loria C, et al. Dietary fat intake and risk of coronary heart disease: the Strong Heart Study. Am I Clin Nutr 2006;84:894-902

52 Virtanen JK, Mursu J, Tuomainen TP, Voutilainen S. Dietary fatty acids and risk of coronary heart disease in men the Kuopio ischemic heart disease risk factor study. Arterioscler Thromb Vasc Biol 2014;34:2679-87.

53 Sauvaget C, Nagano J, Hayashi M, Yamada M. Animal protein, animal fat, and cholesterol intakes and risk of cerebral infarction mortality in the adult health study. Stroke 2004;35:1531-7.

54 Fehily AM, Yarnell JW, Sweetnam PM, Elwood PC. Diet and incident ischaemic heart disease: the Caerphilly Study. Br I Nutr 1993;69:303-14.

55 Howard BV, Van Horn L, Hsia J, et al. Low-fat dietary pattern and risk of cardiovascular disease: the Women's Health Initiative Randomized Controlled Dietary Modification Trial. JAMA 2006;295:655-66.
56 Jakobsen MU, Overvad K, Dyerberg J, Schroll M, Heitmann BL. Dietary fat and risk of coronary heart disease: possible effect modification by gender and age. Am J Epidemiol 2004:160:141-9.

57 Leosdottir M, Nilsson PM, Nilsson JA, Berglund G. Cardiovascular event risk in relation to dietary fat intake in middle-aged individuals: data from The Malmo Diet and Cancer Study. Eur J Cardiovasc Prev Rehabil 2007;14:701-6.

58 McGee D, Reed D, Stemmerman G, Rhoads G, Yano K, Feinleib M. The relationship of dietary fat and cholesterol to mortality in 10 years: the Honolulu Heart Program. Int J Epidemiol 1985:14:97-105.

59 Oh K, Hu FB, Manson JE, Stampfer MJ, Willett WC. Dietary fat intake and risk of coronary heart disease in women: 20 years of follow-up of the nurses' health study. Am I Epidemiol 2005;161:672-9.

60 Posner BM, Cobb JL, Belanger AJ, Cupples LA, D’Agostino RB, Stokes J 3rd. Dietary lipid predictors of coronary heart disease in men. The Framingham Study. Arch Intern Med 1991;151:1181-7.

61 Yamagishi K, Iso H, Kokubo Y, et al. Dietary intake of saturated fatty acids and incident stroke and coronary heart disease in Japanese communities: the JPHC Study. Eur Heart J 2013;34:1225-32.

62 De Goede I, Soedamah-Muthu SS, Trichia E, Geleiinse IM, Kromhout D. Dietary intake of saturated fat by food source and incident coronary heart disease: The zutphen elderly study. Circulation 2015;131.

63 Atkinson C, Whitley E, Ness A, Baker I. Associations between types of dietary fat and fish intake and risk of stroke in the Caerphilly Prospective Study (CaPS). Public Health 2011;125:345-8.

64 Gillman MW, Cupples LA, Millen BE, Ellison RC, Wolf PA. Inverse association of dietary fat with development of ischemic stroke in men. JAMA 1997;278:2145-50.

65 He K, Merchant A, Rimm EB, et al. Dietary fat intake and risk of stroke in male US healthcare professionals: 14 year prospective cohort study. BM/ 2003;327:777-82

66 Misirli G, Benetou V, Lagiou P, Bamia C, Trichopoulos D, Trichopoulou A. Relation of the traditional Mediterranean diet to cerebrovascular disease in a Mediterranean population. Am J Epidemiol 2012;176:1185-92

67 Seino F, Date C, Nakayama T, et al. Dietary lipids and incidence of cerebral infarction in a Japanese rural community. J Nutr Sci Vitaminol (Tokyo) 1997:43:83-99.

68 Wiberg B, Sundstrom J, Arnlov J, et al. Metabolic risk factors for stroke and transient ischemic attacks in middle-aged men: a communitybased study with long-term follow-up. Stroke 2006:37:2898-903.

69 Yaemsiri S, Sen S, Tinker L, Rosamond W, Wassertheil-Smoller S, He K. Trans fat, aspirin, and ischemic stroke in postmenopausal women. Ann Neurol 2012;72:704-15.

70 Yamagishi K, Folsom AR, Steffen LM; ARIC Study Investigators. Plasma fatty acid composition and incidence ischemic stroke in middle-aged adults: the atherosclerosis risk in communities (ARIC) study. Cerebrovasc Dis 2013:36:38-46.

71 Alhazmi A, Stojanovski E, McEvoy M, Garg ML. Macronutrient intake and type 2 diabetes risk in middle-aged Australian women. Results from the Australian Longitudinal Study on Women's Health. Public Health Nutr 2014;17:1587-94.

72 Meyer KA, Kushi LH, Jacobs Jr DR, Folsom AR. Dietary fat and incidence of type 2 diabetes in older lowa women. Diabetes Care 2001;24:1528-35.

73 Salmerón J, Hu FB, Manson JE, et al. Dietary fat intake and risk of type 2 diabetes in women. Am J Clin Nutr 2001;73:1019-26.

74 Simila ME, Kontto JP, Valsta LM, Mannisto S, Albanes D, Virtamo Carbohydrate substitution for fat or protein and risk of type 2 diabetes in male smokers. Eur J Clin Nutr 2012;66:716-21.

75 Song Y, Manson JE, Buring JE, Liu S. A prospective study of red meat consumption and type 2 diabetes in middle-aged and elderly women: The Women's Health study. Diabetes Care 2004;27:2108-15.

76 Van Dam RM, Willett WC, Rimm EB, Stampfer MJ, Hu FB. Dietary fat and meat intake in relation to risk of type 2 diabetes in men. Diabetes Care 2002;25:417-24

77 Lindstrom J, Peltonen M, Eriksson JG, et al. High-fibre, low-fat diet predicts long-term weight loss and decreased type 2 diabetes risk: the Finnish Diabetes Prevention Study. Diabetologia 2006;49:912-20

78 Mahendran Y, Agren J, Uusitupa M, et al. Association of erythrocyte membrane fatty acids with changes in glycemia and risk of type 2 diabetes. Am J Clin Nutr 2014;99:79-85.

79 Kiage JN, Merrill PD, Robinson CJ, et al. Intake of trans fat and all-cause mortality in the Reasons for Geographical and Racial Differences in Stroke (REGARDS) cohort. Am / Clin Nutr 2013;97:1121-28.

80 Oomen CM, Ocke MC, Feskens EJ, van Erp-Baart MA, Kok FJ, Kromhou D. Association between trans fatty acid intake and 10-year risk of coronary heart disease in the Zutphen Elderly Study: a prospective population-based study. Lancet 2001;357:746-51.

81 Kiage JN, Merrill PD, Judd SE, et al. Intake of trans fat and incidence of stroke in the REasons for Geographic And Racial Differences in Stroke (REGARDS) cohort. Am / Clin Nutr 2014:99:1071-6.

82 Wang Q, Imamura F, Ma W, et al. Circulating and dietary trans-fatty acids and incident type-2 diabetes mellitus in older adults: The cardiovascular health study. Circulation 2014:129:1099-107. 
83 Laake I, Pedersen Jl, Selmer R, et al. A prospective study of intake of trans-fatty acids from ruminant fat, partially hydrogenated vegetable oils, and marine oils and mortality from CVD. Br J Nutr 2012;108:743-54

84 Willett WC, Stampfer MJ, Manson JE, , et al. Intake of trans fatty acids and risk of coronary heart disease among women. Lancet 1993;341:581-5.

85 Jakobsen MU, Overvad K, Dyerberg J, Heitmann BL. Intake of ruminant trans fatty acids and risk of coronary heart disease. Int J Epidemiol 2008:37:173-82

86 Mozaffarian D, Cao H, King IB, et al. Trans-palmitoleic acid, metabolic risk factors, and new-onset diabetes in U.S. adults: a cohort study. Ann Intern Med 2010;153:790-9.

87 Mozaffarian D, de Oliveira Otto MC, Lemaitre RN, et al. trans Palmitoleic acid, other dairy fat biomarkers, and incident diabetes: the Multi-Ethnic Study of Atherosclerosis (MESA). Am J Clin Nutr 2013;97:854-61

88 Yakoob MY, Shi P, Hu FB, et al. Circulating biomarkers of dairy fat and incident type 2 diabetes in two U.S. prospective cohort studies. Circulation 2014:129.

89 Santaren ID, Watkins SM, Liese AD, et al. Serum pentadecanoic acid $(15: 0)$, a short-term marker of dairy food intake, is inversely associated with incident type 2 diabetes and its underlying disorders. Am I Clin Nutr 2014:100:1532-40.

90 Centre for Evidence-Based Medicine. Levels of evidence. March 2009. www.cebm.net/oxford-centre-evidence-based-medicine-levelsevidence-march-2009/.

91 Mente A, de Koning L, Shannon HS, Anand SS. A systematic review of the evidence supporting a causal link between dietary factors and coronary heart disease. Arch Intern Med 2009:169:659-69.

92 Micha R, Mozaffarian D. Saturated fat and cardiometabolic risk factors, coronary heart disease, stroke, and diabetes: a fresh look at the evidence. Lipids 2010;45:893-905.

93 Skeaff CM, Miller J. Dietary fat and coronary heart disease: summary of evidence from prospective cohort and randomised controlled trials. Ann Nutr Metab 2009;55:173-201.

94 Mensink RP, Zock PL, Kester ADM, Katan MB. Effects of dietary fatty acids and carbohydrates on the ratio of serum total to HDL cholesterol and on serum lipids and apolipoproteins: a meta-analysis of 60 controlled trials. Am J Clin Nutr 2003;77:1146-55.

95 Stamler J, Wentworth D, Neaton JD. Is relationship between serum cholesterol and risk of premature death from coronary heart disease continuous and graded? Findings in 356,222 primary screenees of the Multiple Risk Factor Intervention Trial (MRFIT). JAMA

1986;256:2823-8

96 Kannel WB, Neaton JD, Wentworth D, et al. Overall and coronary heart disease mortality rates in relation to major risk factors in 325,348 men screened for the MRFIT. Multiple Risk Factor Intervention Trial. Am Heart/ 1986;112:825-36

97 Gordon T, Kannel WB, Castelli WP, Dawber TR. Lipoproteins, cardiovascular disease, and death. The Framingham study. Arch Intern Med 1981;141:1128-31.

98 Giovannucci E, Rimm EB, Stampfer MJ, Colditz GA, Ascherio A, Willett WC. Intake of fat, meat, and fiber in relation to risk of colon cancer in men. Cancer Res 1994;54:2390-7.

99 Smith-Warner SA, Spiegelman D, Adami HO, et al. Types of dietary fa and breast cancer: a pooled analysis of cohort studies. Int J Cancer 2001;92:767-74.

100 Larsson SC, Orsini N. Red meat and processed meat consumption and all-cause mortality: a meta-analysis. Am J Epidemiol 2013.

101 O'Sullivan TA, Hafekost K, Mitrou F, Lawrence D. Food sources of saturated fat and the association with mortality: a meta-analysis. Am J Public Health 2013;103:e31-42.

102 Rohrmann S, Overvad K, Bueno-de-Mesquita HB, et al. Meat consumption and mortality-results from the European Prospective Investigation into Cancer and Nutrition. BMC Med 2013;11:63.

103 Zhu H, Yang X, Zhang C, et al. Red and processed meat intake is associated with higher gastric cancer risk: a meta-analysis of epidemiological observational studies. PLoS One 2013;8:e70955.

104 Choi Y, Song S, Song Y, Lee JE. Consumption of red and processed meat and esophageal cancer risk: meta-analysis. World J Gastroenterol 2013:19:1020-9.

105 Aune D, Chan DS, Vieira AR, et al. Red and processed meat intake and risk of colorectal adenomas: a systematic review and meta-analysis of epidemiological studies. Cancer Causes Control 2013;24:611-27.

106 World Cancer Research Fund/American Institute for Cancer Research. Food, nutrition, physical activity, and the prevention of cancer: a global Perspective. World Cancer Research Fund/American Institute for Cancer Research, 2007.

107 Tanasescu M, Cho E, Manson JE, Hu FB. Dietary fat and cholesterol and the risk of cardiovascular disease among women with type 2 diabetes. Am / Clin Nutr 2004:79:999-1005.

108 Trichopoulou A, Psaltopoulou T, Orfanos P, Trichopoulos D. Diet and physical activity in relation to overall mortality amongst adult diabetics in a general population cohort. J Intern Med 2006;259:583-91.
109 Lichtenstein AH, Schwab US. Relationship of dietary fat to glucose metabolism. Atherosclerosis 2000;150:227-43.

110 Franz MJ, Bantle JP, Beebe CA, et al. Evidence-based nutrition principles and recommendations for the treatment and prevention of diabetes and related complications. Diabetes Care 2003;26 Suppl 1.S51-61.

111 Jakobsen MU, O'Reilly EJ, Heitmann BL, et al. Major types of dietary fat and risk of coronary heart disease: a pooled analysis of 11 cohort studies. Am J Clin Nutr 2009;89:1425-32.

112 Dayton S, Pearce ML, Hashimoto S, Dixon WJ, Tomiyasu U. A controlled clinical trial of a diet high in unsaturated fat in preventing complications of atherosclerosis. Circulation 1969;40:II-1-II-63.

113 Leren P. The Oslo diet-heart study. Eleven-year report. Circulation 1970;42:935-42.

114 Turpeinen O, Karvonen MJ, Pekkarinen M, Miettinen M, Elosuo R, Paavilainen E. Dietary prevention of coronary heart disease: the Finnish Mental Hospital Study. Int J Epidemiol 1979;8:99-118.

115 Liu S, Willett WC, Stampfer MJ, et al. A prospective study of dietary glycemic load, carbohydrate intake, and risk of coronary heart disease in US women. Am J Clin Nutr 2000;71:1455-61.

116 Jakobsen MU, Dethlefsen C, Joensen AM, et al. Intake of carbohydrates compared with intake of saturated fatty acids and risk of myocardial infarction: importance of the glycemic index. Am J Clin Nutr 2010:91:1764-8

117 Hu FB, Stampfer MJ, Manson JE, et al. Dietary saturated fats and their food sources in relation to the risk of coronary heart disease in women. Am / Clin Nutr 1999;70:1001-8.

118 De Oliveira Otto MC, Mozaffarian D, et al. Dietary intake of saturated fat by food source and incident cardiovascular disease: the Multi-Ethnic Study of Atherosclerosis. Am J Clin Nutr 2012;96:397-404.

119 Rasmussen BM, Vessby B, Uusitupa M, et al. Effects of dietary saturated, monounsaturated, and n-3 fatty acids on blood pressure in healthy subjects. Am I Clin Nutr 2006;83:221-6.

120 Riserus U. Fatty acids and insulin sensitivity. Curr Opin Clin Nutr Metab Care 2008;11:100-5

121 Perez-limenez F, Lopez-Miranda J, Pinillos MD et al. A Mediterranean and a high-carbohydrate diet improve glucose metabolism in healthy young persons. Diabetologia 2001;44:2038-43.

12 Vessby B, Uusitupa M, Hermansen K, et al. Substituting dietary saturated for monounsaturated fat impairs insulin sensitivity in healthy men and women: The KANWU Study. Diabetologia 2001;44:312-9.

123 Tinker LF, Bonds DE, Margolis KL, et al. Low-fat dietary pattern and risk of treated diabetes mellitus in postmenopausal women: the Women's Health Initiative randomized controlled dietary modification trial. Arch Intern Med 2008;168:1500-11.

124 Pan A, Sun Q, Bernstein AM, Manson JE, Willett WC, Hu FB. Changes in red meat consumption and subsequent risk of type 2 diabetes mellitus: three cohorts of US men and women. JAMA Intern Med 2013;173:1328-35.

125 Micha R, Michas G, Mozaffarian D. Unprocessed red and processed meats and risk of coronary artery disease and type 2 diabetes-an updated review of the evidence. Curr Atheroscler Rep 2012;14:515-24.

126 Lee JE, McLerran DF, Rolland B, et al. Meat intake and cause-specific mortality: a pooled analysis of Asian prospective cohort studies. Am J Clin Nutr 2013;98:1032-41.

127 Forouhi NG, Koulman A, Sharp SJ, et al. Differences in the prospective association between individual plasma phospholipid saturated fatty acids and incident type 2 diabetes: the EPIC-InterAct case-cohort study. Lancet Diabetes Endocrinol 2014:2:810-8.

128 Turcot V, Brunet J, Daneault C, Tardif JC, Des Rosiers C, Lettre G. Validation of fatty acid intakes estimated by a food frequency questionnaire using erythrocyte fatty acid profiling in the Montreal Heart Institute Biobank. J Hum Nutr Diet 2014. www.ncbi.nlm.nih.gov/ pubmed/25208630

129 Wennberg M, Vessby B, Johansson I. Evaluation of relative intake of fatty acids according to the Northern Sweden FFQ with fatty acid levels in erythrocyte membranes as biomarkers. Public Health Nutr 2009;12:1477-84.

130 Sluijs I, Forouhi NG, Beulens JW, et al. The amount and type of dairy product intake and incident type 2 diabetes: results from the EPIC-InterAct Study. Am J Clin Nutr 2012;96:382-90.

131 O'Connor LM, Lentjes MA, Luben RN, Khaw KT, Wareham NJ, Forouhi NG. Dietary dairy product intake and incident type 2 diabetes: a prospective study using dietary data from a 7-day food diary. Diabetologia 2014;57:909-17.

132 Hudgins LC, Hellerstein M, Seidman C, Neese R, Diakun J, Hirsch . Human fatty acid synthesis is stimulated by a eucaloric low fat, high carbohydrate diet. J Clin Invest 1996;97:2081-91.

133 Siler SQ, Neese RA, Hellerstein MK. De novo lipogenesis, lipid kinetics, and whole-body lipid balances in humans after acute alcohol consumption. Am J Clin Nutr 1999;70:928-36.

134 Hodson L, Skeaff CM, Fielding BA. Fatty acid composition of adipose tissue and blood in humans and its use as a biomarker of dietary intake. Prog Lipid Res 2008;47:348-80. 
135 Sharma RB, Alonso LC. Lipotoxicity in the pancreatic beta cell: not just survival and function, but proliferation as well? Curr Diab Rep 2014:14:492.

136 Willett WC, Ascherio A. Trans fatty acids: are the effects only marginal? Am J Public Health 1994;84:722-4.

137 Danaei G, Ding EL, Mozaffarian D et al. The preventable causes of death in the United States: comparative risk assessment of dietary, lifestyle, and metabolic risk factors. PLoS Med 2009;6:e1000058.

138 Chiuve SE, Rimm EB, Manson JE, et al. Intake of total trans, trans-18:1, and trans-18:2 fatty acids and risk of sudden cardiac death in women. Am Heart J 2009;158:761-7.

139 Vinikoor LC, Millikan RC, Satia JA, et al. trans-Fatty acid consumption and its association with distal colorectal cancer in the North Carolina Colon Cancer Study II. Cancer Causes Control 2010;21:171-80.

140 Chajes V, Thiebaut AC, Rotival M, et al. Association between serum trans-monounsaturated fatty acids and breast cancer risk in the E3N-EPIC Study. Am I Epidemiol 2008;167:1312-20.

141 Mozaffarian D, Katan MB, Ascherio A, Stampfer MJ, Willett WC. Trans fatty acids and cardiovascular disease. N Engl J Med 2006;354:1601-13.

142 Abbey M, Nestel P. Plasma cholesteryl ester transfer protein activity is increased when trans-elaidic acid is substituted for cis-oleic acid in the diet. Atherosclerosis 1994;106:99-107.

143 Mensink RP, Zock PL, Kester ADM, Katan MB. Effects of dietary fatty acids and carbohydrates on the ratio of serum total to HDL cholestero and on serum lipids and apolipoproteins: a meta-analysis of 60 controlled trials. Am J Clin Nutr 2003;77:1146-55.

144 Katan MB, Zock PL, Mensink RP. Trans fatty acids and their effects on lipoproteins in humans. Annu Rev Nutr 1995;15:473-93.

145 Mauger JF, Lichtenstein AH, Ausman LM, et al. Effect of different forms of dietary hydrogenated fats on LDL particle size. Am J Clin Nutr 2003;78:370-5

146 Baer DJ, Judd JT, Clevidence BA, Tracy RP. Dietary fatty acids affect plasma markers of inflammation in healthy men fed controlled diets: a randomized crossover study. Am I Clin Nutr 2004;79:969-73.

147 Libby P, Ridker PM, Hansson GK, Leducq Transatlantic Network on Atherothrombosis. Inflammation in atherosclerosis: from pathophysiology to practice. / Am Coll Cardiol 2009;54:2129-38.

148 Mozaffarian D, Rimm EB, King IB, Lawler RL, McDonald GB, Levy WC. Trans fatty acids and systemic inflammation in heart failure. Am J Clin Nutr 2004;80:1521-5.

149 Wang Q, Imamura F, Lemaitre RN, et al. Plasma phospholipid trans-fatty acids levels, cardiovascular diseases, and total mortality: the cardiovascular health study. J Am Heart Assoc 2014:3:pii:e000914.

150 Aronis KN, Khan SM, Mantzoros CS. Effects of trans fatty acids on glucose homeostasis: a meta-analysis of randomized, placebocontrolled clinical trials. Am I Clin Nutr 2012:96:1093-9.

151 Dong JY, Xun P, He K, Qin LQ. Magnesium intake and risk of type 2 diabetes: meta-analysis of prospective cohort studies. Diabetes Care 2011;34:2116-22

152 Schulze MB, Schulz M, Heidemann C, Schienkiewitz A, Hoffmann K, Boeing $\mathrm{H}$. Fiber and magnesium intake and incidence of type 2 diabetes: a prospective study and meta-analysis. Arch Intern Med 2007:167:956-65.

$153 \mathrm{Cao}$ H, Gerhold K, Mayers JR, Wiest MM, Watkins SM, Hotamisligil GS. Identification of a lipokine, a lipid hormone linking adipose tissue to systemic metabolism. Cell 2008;134:933-44.

154 Gayet-Boyer C, Tenenhaus-Aziza F, Prunet C, et al. Is there a linear relationship between the dose of ruminant trans-fatty acids and cardiovascular risk markers in healthy subjects: results from a systematic review and meta-regression of randomised clinical trials. Br J Nutr 2014:112:1914-22.

155 Colon-Ramos U, Baylin A, Campos H. The relation between trans fatty acid levels and increased risk of myocardial infarction does not hold at lower levels of trans fatty acids in the Costa Rican food supply. J Nutr 2006;136:2887-92

156 Clifton PM, Keogh JB, Noakes M. Trans fatty acids in adipose tissue and the food supply are associated with myocardial infarction. [erratum appears in J Nutr 2004 Jul;134:1848]. J Nutr 2004; 134:874-9.

157 Baylin A, Kabagambe EK, Ascherio A, Spiegelman D, Campos H. High 18:2 trans-fatty acids in adipose tissue are associated with increased risk of nonfatal acute myocardial infarction in costa rican adults. J Nutr 2003;133:1186-91.

158 Block RC, Harris WS, Reid KJ, Spertus JA. Omega- 6 and trans fatty acids in blood cell membranes: a risk factor for acute coronary syndromes? Am Heart J 2008;156:1117-23.

159 Ghahremanpour F, Firoozrai M, Darabi M, Zavarei A, Mohebbi A. Adipose tissue trans fatty acids and risk of coronary artery disease: a case-control study. Ann Nutr Metab 2008;52:24-8.

160 Park Y, Lim J, Lee J, Kim S-G. Erythrocyte fatty acid profiles can predict acute non-fatal myocardial infarction. Br / Nutr 2009:102:1355-61.
161 Van de Vijver LP, van Poppel G, van Houwelingen A, Kruyssen DA, Hornstra G. Trans unsaturated fatty acids in plasma phospholipids and coronary heart disease: a case-control study. Atherosclerosis 1996;126:155-61.

162 Aro A, Kardinaal AF, Salminen I, et al. Adipose tissue isomeric trans fatty acids and risk of myocardial infarction in nine countries: the EURAMIC study. Lancet 1995;345:273-8.

163 Micha R, King IB, Lemaitre RN, et al. Food sources of individual plasma phospholipid trans fatty acid isomers: the Cardiovascular Health Study. Am / Clin Nutr 2010;91:883-93.

164 Allison DB, Egan SK, Barraj LM, Caughman C, Infante M, Heimbach JT. Estimated intakes of trans fatty and other fatty acids in the US population. / Am Diet Assoc 1999:99:166-746.

165 Mozaffarian D, Abdollahi M, Campos H, Houshiarrad A, Willett WC. Consumption of trans fats and estimated effects on coronary heart disease in Iran. Eur J Clin Nutr 2007;61:1004-10.

166 Kemeny ZRK, Henon G, Kovari K, Zwobada F. Deodorization of vegetable oils: prediction of trans polyunsaturated fatty acid content. J Am Oil Chem Soc 2001;78:973-79.

167 Sun Q Mal, Campos H, Hu FB. Plasma and erythrocyte biomarkers of dairy fat intake and risk of ischemic heart disease. Am J Clin Nutr 2007;86:929-37.

168 Khaw KT, Friesen MD, Riboli E, Luben R, Wareham N. Plasma phospholipid fatty acid concentration and incident coronary heart disease in men and women: The EPIC-Norfolk prospective study. PLoS Med 2012;9.

169 Lemaitre RN, King IB, Mozaffarian D, et al. Plasma phospholipid trans fatty acids, fatal ischemic heart disease, and sudden cardiac death in older adults: the cardiovascular health study. Circulation 2006;114:209-15.

170 Hodge AM, English DR, O’Dea K, et al. Plasma phospholipid and dietary fatty acids as predictors of type 2 diabetes: interpreting the role of linoleic acid. Am J Clin Nutr 2007;86:189-97.

171 Kroger J, Zietemann V, Enzenbach C, et al. Erythrocyte membrane phospholipid fatty acids, desaturase activity, and dietary fatty acids in relation to risk of type 2 diabetes in the European Prospective Investigation into Cancer and Nutrition (EPIC)-Potsdam Study. Am J Clin Nutr 2011;93:127-42.

172 Patel PS, Sharp SJ, Jansen E, et al. Fatty acids measured in plasma and erythrocyte-membrane phospholipids and derived by food-frequency questionnaire and the risk of new-onset type 2 diabetes: a pilot study in the European Prospective Investigation into Cancer and Nutrition (EPIC)-Norfolk cohort. Am J Clin Nutr 2010;92:1214-22.

173 Svensson L, Sisfontes L, Nyborg G, Blomstrand R. High performance liquid chromatography and glass capillary gas chromatography of geometric and positional isomers of long chain monounsaturated fatty acids. Lipids 1981;17:50-9.

174 Stamler J. Diet-heart: a problematic revisit. Am / Clin Nutr 2010;91:497-9.

175 Scarborough P, Rayner M, van Dis I, Norum K. Meta-analysis of effect of saturated fat intake on cardiovascular disease: overadjustment obscures true associations. Am / Clin Nutr 2010;92:458-9.

176 Alhazmi A, Stojanovski E, McEvoy M, Garg ML. Macronutrient intakes and development of type 2 diabetes: a systematic review and meta-analysis of cohort studies. I Am Coll Nutr 2012;31:243-58.

177 Hu FB. Are refined carbohydrates worse than saturated fat? Am J Clin Nutr 2010;91:1541-2.

178 Farvid MS, Ding M, Pan A, et al. Dietary linoleic acid and risk of coronary heart disease: a systematic review and metaanalysis of prospective cohort studies. Circulation 2014;130:1568-78.

179 Ramsden CE, Zamora D, Leelarthaepin B, et al. Use of dietary linoleic acid for secondary prevention of coronary heart disease and death: evaluation of recovered data from the Sydney Diet Heart Study and updated meta-analysis. BMJ 2013;346:e8707.

(C) BMJ Publishing Group Ltd 2015

Appendix 1: Search strategies and data extractions forms

Appendix 2: Supplementary tables (eTables 1-20)

Appendix 3: Evidence reviewed but did not inform GRADE evidence summary

Appendix 4: Supplementary figures (eFigures 1-68)

Appendix 5: GRADE evidence profile for prospective cohort studies of saturated fatty acids and health outcomes

Appendix 6: GRADE evidence profile for prospective cohort studies of trans fatty acids and health outcomes 